\title{
Poised cell circuits in human skin are activated in disease
}

Gary Reynolds $^{1 \dagger}$, Peter Vegh ${ }^{1 \dagger}$, James Fletcher ${ }^{1 \dagger}$, Elizabeth F.M. Poyner ${ }^{1,2 \dagger}$, Emily Stephenson ${ }^{1}$, Issac Goh ${ }^{1}$, Rachel A. Botting ${ }^{1}$, Ni Huang ${ }^{3}$, Bayanne Olabi ${ }^{1,4}$, Anna Dubois ${ }^{1,2}$, David Dixon ${ }^{1}$, Kile Green ${ }^{1}$, Daniel Maunder ${ }^{1}$, Justin Engelbert ${ }^{1}$, Mirjana Efremova ${ }^{3}$, Krzysztof Polański ${ }^{3}$, Laura Jardine $^{1}$, Claire Jones ${ }^{1}$, Thomas Ness ${ }^{1}$, Dave Horsfall ${ }^{1}$, Jim McGrath ${ }^{1}$, Christopher Carey ${ }^{1}$, Dorin-Mirel Popescu ${ }^{1}$, Simone Webb ${ }^{1}$, Xiao-nong Wang ${ }^{1}$, Ben Sayer ${ }^{1}$, Jong-Eun Park ${ }^{3}$, Victor A. Negri ${ }^{5}$, Daria Belokhvostova ${ }^{5}$, Magnus Lynch ${ }^{5}$, David McDonald ${ }^{1}$, Andrew Filby ${ }^{1}$, Tzachi Hagai $^{3}$, Kerstin B. Meyer ${ }^{3}$, Akhtar Husain ${ }^{6}$, Jonathan Coxhead ${ }^{1}$, Roser Vento-Tormo ${ }^{3}$, Sam Behjati $^{3,7}$, Steven Lisgo ${ }^{1}$, Alexandra-Chloé Villani ${ }^{8}$, Jaume Bacardit ${ }^{9}$, Phil Jones ${ }^{3,10}$, Edel A. O’Toole ${ }^{11}$, Graham S. Ogg ${ }^{12}$, Neil Rajan ${ }^{1,2}$, Nick J. Reynolds ${ }^{2,13}$, Sarah A. Teichmann ${ }^{3,14 *}$, Fiona Watt ${ }^{5 *}$, Muzlifah Haniffa ${ }^{1,2,3 *}$

\section{Affiliations:}

${ }^{1}$ Biosciences Institute, Newcastle University, Newcastle upon Tyne, NE2 4HH, UK ${ }^{2}$ Department of Dermatology and NIHR Newcastle Biomedical Research Centre, Newcastle Hospitals NHS Foundation Trust, Newcastle upon Tyne NE2 4LP, UK

${ }^{3}$ Wellcome Sanger Institute, Wellcome Genome Campus, Hinxton, Cambridge CB10 1SA, UK ${ }^{4}$ Department of Dermatology, NHS Lothian, Lauriston Building, Lauriston Place, Edinburgh, EH3 9EN

${ }^{5}$ Centre for Stem Cells and Regenerative Medicine, King's College London, Guy's Hospital Campus, London SE1 9RT

${ }^{6}$ Department of Pathology, Royal Victoria Infirmary, Newcastle upon Tyne NE1 4LP, UK ${ }^{7}$ Department of Paediatrics, University of Cambridge, Cambridge CB2 0SP, UK

${ }^{8}$ Broad Institute of Harvard and MIT, Cambridge, MA 02142, USA; Center for Immunology and Inflammatory Diseases, Massachusetts General Hospital, Boston, MA 02129, USA

${ }^{9}$ School of Computing, Newcastle University, NE4 5TG, UK

${ }^{10} \mathrm{MRC}$ Cancer Unit, University of Cambridge, Cambridge CB2 0XZ

${ }^{11}$ Centre for Cell Biology and Cutaneous Research, Blizard Institute, Queen Mary University of London, UK

${ }^{12}$ MRC Human Immunology Unit, Oxford Biomedical Research Centre, MRC Weatherall Institute of Molecular Medicine, University of Oxford, UK

${ }^{13}$ Translational and Clinical Research Institute, Newcastle University, Newcastle upon Tyne, NE2 4HH, UK

${ }^{14}$ Theory of Condensed Matter Group, Cavendish Laboratory/Department of Physics, University of Cambridge, Cambridge CB3 0HE, UK

*Corresponding authors,

'Equal contribution 
Abstract: The human skin confers biophysical and immunological protection through a complex cellular network that is established early in development. We profiled $\sim 500,000$ single cells using RNA-sequencing from healthy adult and developing skin, and skin from patients with atopic dermatitis and psoriasis. Our findings reveal a predominance of innate lymphoid cells and macrophages in developing skin in contrast to T cells and migratory dendritic cells in adult skin. We demonstrate dual keratinocyte differentiation trajectories and activated cellular circuits comprising vascular endothelial cells mediating immune cell trafficking, disease-specific clonally expanded IL13/IL22 and IL17A/F-expressing lymphocytes, epidermal IL23-expressing dendritic cells and inflammatory keratinocytes in disease. Our findings provide key insights into the dynamic cellular landscape of human skin in health and disease.

One Sentence Summary: Single cell atlas of human skin reveals cell circuits which are quantitatively and qualitatively reconfigured in inflammatory skin disease. 


\section{Introduction}

Human skin undergoes dramatic adaptation as it transitions from a relatively sterile aquatic environment in utero to provide mechanical and immunological protection in a non-sterile terrestrial environment. This function requires coordination by specialized cell types that are organized within the unique skin architecture. The vast majority of leukocytes within skin are regionally mobile and also capable of trafficking to and from other parts of the organism through blood and lymphatic vessels (1). There is continuous trafficking of leukocytes across the basement membrane (2), which separates the epidermis, primarily composed of keratinocytes, from the dermis, comprising stroma, appendageal structures and vessels. Epidermal keratinocytes undergoing differentiation are desquamated over 30-60 days and are replenished by stem cells in the basal layer, whose progeny move upwards to the superficial stratum corneum (3).

Recent insights into the origin of immune cells in the skin have suggested seeding of some leukocytes during embryonic development that can persist into adulthood (4). The persistence or function of embryonic-derived cells in skin homeostasis or pathology in adult life is unclear.

The contribution of non-leukocytes such as keratinocytes and fibroblasts to cutaneous immunity and immunological memory has revolutionized our understanding of the human skin (5). Current consensus view on inflammatory skin disease pathogenesis such as atopic dermatitis (AD) and psoriasis supports the interplay between leukocytes and non-leukocytes in disease initiation and progression (6). This knowledge has been primarily derived from whole disease skin transcriptome analysis, which identified the signature pathways for $\mathrm{AD}$ (Th2/Th22) and psoriasis (Th17) and their resolution following treatment (7). However, the precise cellular interactions mediating these pathways remain unresolved.

Single cell technological advances such as RNA-sequencing provide a new opportunity to dissect the complex cellular organization in human skin in health and disease at a systems level. The limited studies so far have focused on the epidermis (8), relatively small cell numbers from dissociated dermis or whole skin (9) and have not integrated multiplexed protein analysis. In this study, we used single cell RNA-sequencing (scRNA-seq) to comprehensively define the landscape 
of the immune networks within early development and healthy adult skin, and characterize the reconfigured cell circuits in two common inflammatory skin disorders, AD and psoriasis.

\section{Results}

\section{Deconstructing human skin}

We performed comprehensive single cell analysis of healthy human skin using scRNA-seq and mass cytometry. To maximize cell yield and viability from tissue dissociation, we used $200 \mu \mathrm{m}$ thick pieces of mammoplasty skin which were separated into epidermis and dermis prior to enzymatic dissociation (Fig. 1 and Fig. S1A). We leveraged known surface markers defining the different skin cellular compartments to profile live, single cells from each contiguously placed FACS gates containing non-immune cells (keratinocytes, fibroblasts, and endothelial cells) and immune cells (myeloid and lymphoid cells) (Fig. S1B) from the epidermis and dermis for droplet encapsulation (10x Genomics) profiling. We also performed indexed plate-based Smart-seq2 profiling of all epidermal and dermal cells within the $\mathrm{CD} 45^{+} \mathrm{HLA}-\mathrm{DR}^{+}$myeloid gate (Fig. S1B). To compare cell states in healthy skin with inflammatory disease induced perturbation, we performed scRNA-seq (10x Genomics) on all CD45 ${ }^{+/-}$cells from lesional and non-lesional skin from $\mathrm{AD}$ and psoriasis patients (Fig. 1A and Fig. S1B-E).

In total, 528,253 sequenced skin cells $(n=19)$ passed quality control (QC) and doublet exclusion (Fig. 1A and Fig. S2). We detected on average $\sim 3,000$ genes with the 10x Genomics platform and $\sim 6,000$ genes per cell with the Smart-seq2 protocol (see Methods and Fig. S2). We excluded cells with $<200$ genes, $>20 \%$ mitochondrial gene expression and those identified as doublets (see

Methods). To account for biases due to batch effects we performed data integration of healthy skin samples using BBKNN implementation within Scanpy $(10,11)$, which showed good mixing by UMAP visualization (Fig. 1B and Fig. S2A). We performed graph-based Leiden clustering and derived differentially expressed genes to annotate the cell clusters, from which 34 cell states were identified (Fig. 1B-C). We selected genes encoding surface proteins (denoted by * in Fig. 1C) and additional antigens where antibodies are commercially available, to derive a CyTOF panel for protein level validation of the cell categories on 4 additional donors (Fig. S3A-F). Using CyTOF analysis, we were able to evaluate the frequency of cell types in healthy adult skin (Fig. S3E). 
To evaluate the establishment of specific cell types during development and the temporal evolution

of the cell types found in adult skin, we compared our adult skin scRNA-seq data with our 7-10 post-conception weeks (PCW) $(n=7)$ embryonic/fetal scRNA-seq datasets (12). We used the TransferAnchors function in Seurat to integrate adult and fetal skin cell states (Fig. 1E) $(13,14)$ and calculated proportional representation of the equivalent cell states in healthy developing and adult skin (Fig. 1D-F).

\section{Stromal cellular circuits}

We next interrogated the heterogeneity within fibroblasts, vascular and lymphatic endothelial cells and Schwann cells (Fig. 2A-B). Fibroblasts dominated the non-immune cell population in developing skin with increased proportional representation of melanocytes, Schwann cells and lymphatic and vascular endothelial cells observed in adult skin (Fig. 1F).

Melanocytes are characterized by expression of PMEL, TYR, TYRP1, DCT1 and MLANA (Fig. 1B-C and 2B). In fetal skin, these cells express higher levels of MITF, PMEL and TYRPI but lower levels of TYR and DCT (Fig. 2B) suggesting an immature melanoblast-like profile (15). Schwann cells form two clusters, Schwann1 (expressing myelinating genes including FLG2, $N G R F$ and SOX10) and Schwann2, which co-express Schwann cell markers (NGRF) and fibroblast markers ( $D C N, F G F 7)$, and match the DEG profile of cells previously described as a rare fibroblast subset (Fig. 2B)(16).

Three fibroblast subsets expressing extracellular matrix (ECM)-related genes such as $M M P 2$, COL1A1, COL1A2 and NT5E (encodes CD73) are present in healthy human skin dominated by F1 and F3 fibroblasts and a minor population of F2 fibroblasts (Fig. 1B-C and 2A-B). All three also co-express immunomodulatory genes. F1 and F3 fibroblasts express TNFAIP6, IL6 and CXCL1, as well as higher levels of MT2A and PTGES (Fig. 1C, 2B and Table S1). F3 fibroblasts share the immunomodulatory gene signature associated with F1 fibroblasts but also express higher levels of 
CD82 (apoptotic), CCL19 (chemotaxis), as well as wound healing-associated genes including TNC and TGFB3 (17) (Fig. 2B, Table S1). In contrast to F1 and F3, immunomodulatory genes expressed by F2 fibroblasts include chemokines CXCL3 and CXCL12, involved in monocyte migration and leukocyte inflammation respectively, suggesting additional roles of immune cell recruitment (Fig. 2B). Dermal fibroblast heterogeneity encompassing structural and immunomodulatory subtypes has been previously reported at single cell level (9, 16). Interestingly, fibroblasts in fetal skin express more genes relating to F2 fibroblasts, including COL1A1, COL1A2 and COL6A1, suggesting they are functionally specialized towards ECM remodeling and maintenance (Fig. 2B). Furthermore, in AD and psoriasis lesional and nonlesional skin, F2 fibroblasts are significantly enriched compared to healthy skin and have upregulated expression of the chemokines CXCL12 and CCL19 (Fig. S4A).

\section{Specialized vascular endothelium mediates leukocyte trafficking}

Endothelial cells in the healthy adult dermis comprise vascular endothelium (PECAM1, EMCN) and lymphatic endothelium ( $L Y V E 1, P D P N)$ (Fig. 2A-B and Table S1). Pericytes expressing RGS5, MCAM and PDGFRB and exhibiting mixed endothelium (SERPINE1, VEGFA) and smooth muscle $(K C N J 8, H I P K 2)$ features are also present (Fig. 2A-B and Table S1).

There are two sub-clusters of lymphatic endothelial cells defined by the differential expression of LYVE1 and PDPN, which are higher in LE1 and LE2 respectively (Fig. 2A-B). We previously reported LYVE1 expression to identify initial afferent lymphatics that drain into $\mathrm{PDPN}^{+}$collecting lymphatic vessels in human dermis (18). Notably, LE1 cells express higher levels of the chemoattractant CCL21, which mediates dendritic cell (DC) migration into skin draining lymph nodes, as well as angiogenesis factors $C A V I N 2$ and $C C N D 1$, further supporting their function as initial afferent lymphatics (19) (Fig. 2A-B and Table S1). LE2 cells can also be differentiated from LE1 by higher expression of GBP2 and SOD2 (Fig. 2B).

Three distinct states of PECAM1 (CD31)-expressing vascular endothelial cells are present in adult dermis. ACKR1 expression in VE2, a marker of venular capillary cells, is distinguishable from HEY1-expressing VE1, which correspond to non-venular capillary cells (20)(Fig. 2B). A third cluster, VE3, which forms $\sim 2 \%$ of endothelial cells, is characterized by gamma synuclein (SNCG), 
the venular capillary marker $A C K R l$ and inflammatory cytokines, chemokines and leukocyte adhesion molecules including IL6, IL33, SELE and ICAMI (Fig. 2B).

We hypothesized that VE3 may demarcate vascular endothelial cells mediating leukocyte adhesion and extravasation into the dermis. We performed whole-mount immunostaining of healthy dermis and identified $\mathrm{SNCG}^{+} \mathrm{PECAM}^{+}(\mathrm{VE} 3)$ distended vascular structures in the superficial dermis (Fig. 2C). Our findings support localized vascular endothelial areas consisting primarily of VE3 specialized in leukocyte adhesion and trafficking (Fig. 2C). Notably, SNCG expression has been reported in malignant melanoma-associated endothelial cells (21), decreased microtubule rigidity (22) and cancer metastases (23). To further investigate the potential role for VE3 in leukocyte trafficking, we used our receptor-ligand computational framework (CellPhoneDB)(24, 25) to evaluate specifically enriched interactions between VE3 and skin DCs and T cells. VE3 was enriched for the expression of receptors involved in leukocyte adhesion, migration and chemotaxis, in contrast to VE1 and VE2 (Fig. S4B).

Both LE and VE are present in 7 PCW fetal skin, earlier than previous studies using 8-10 PCW skin (26). Fetal lymphatic endothelial cells have lower expression of LYVE1, PDPN and CCL21 suggesting that they are functionally immature (Fig. 2B). Interestingly, fetal VE cells aligned with adult VE3 (Fig. 1E) although they do not express $S N C G$ (Figure 2B). We observed two pericyte states in healthy adult skin (Fig. 1B and 2B). Fetal pericytes aligned with pericyte2 (Fig. 1E).

Pericyte 2 and VE3 are significantly expanded in AD and psoriasis lesional and non-lesional skin (Fig. 2D). To explore the qualitative differences and cell-cell interactions between pericytes and VE3 in healthy and inflamed skin, we interrogated the DEG of pericyte2 and VE3 between AD and psoriasis versus healthy adult skin respectively. Pathway enrichment analysis of these differentially expressed genes revealed shared and distinct gene sets in AD and psoriasis lesional skin pericyte2 and VE3 (Fig. 2E). Pericyte2 in AD lesional skin is enriched for leukocyte recruitment and inflammatory responses including TNF $\alpha$-mediated signaling. Pericyte 2 in psoriasis is enriched for neutrophil chemotaxis and stress-response pathways relating to IL-6, and JAK-STAT signaling. VE3 in AD and psoriasis is enriched for leukocyte migration, angiogenesis and stress response pathways. In psoriasis, calcium ion transport-related pathways and lipid 
biosynthetic responses are also enriched (Fig. 2E). As leukocyte chemotaxis featured prominently in the upregulated gene sets in disease, we leveraged CellPhoneDB to establish the receptor-ligand pair interactions between pericyte2 and VE3 and immune cells in AD and psoriasis. which identified CXCL12:CXCR4 and SELE/P:SELPLG involvement (Fig. S4C).

\section{Keratinocyte differentiation in healthy and diseased skin}

Further clustering analysis of keratinocytes identified four subgroups corresponding primarily to different proliferative stages of keratinocytes (Fig. 3A). Pre-proliferative keratinocytes transcribe basal layer proteins such as KRT5 and KRT14 and are abundant in our CD49f ${ }^{\text {hi }}$ gate that was used to enrich for basal cells in the epidermis (27) (Fig. 1C). Our data identifies CTNNAL1 (alphacatulin) as a novel marker of pre-proliferative keratinocytes (Fig. 3B). In mice, depletion of the related protein, alpha-catenin, upregulated keratinocyte proliferation (28). The proliferating keratinocytes have a mixed signature of basal cell transcripts with low level expression of suprabasal cell transcripts, such as KRT1. They are characterized by $C D K 1$ and PCNA (Fig. 3BC). Post-proliferative keratinocytes express suprabasal layer genes, such as KRT1 and KRT10 (Fig. 3B-C). The gene expression patterns of these keratinocyte subgroups are in agreement with their spatial arrangement in the epidermis (Fig. 3C)(Human Protein Atlas: www.proteinatlas.org). We observe similar keratinocyte subgroups in a recently published human epidermal cell scRNA-seq dataset (8)(Fig. S5A). In addition, we identify a cluster of post-proliferative keratinocytes characterized by the expression of immunomodulatory genes, including CCL20, ICAMI and TNF (Fig. 3A and C). In agreement with our analysis of $200 \mu \mathrm{m}$-deep mammoplasty skin we did not detect hair follicles by histochemical staining (Fig. S1A), or bulb and infundibular cells by scRNAseq, which are found deeper in the skin and are more abundant in other anatomical sites (29).

Corresponding analysis of fetal skin shows mixed expression of basal and suprabasal transcripts by fetal keratinocytes (Fig. 3B), which comprise two cell layers between 7-10 PCW (Fig. S5B). This agrees with histological descriptions of fetal skin comprising an ectodermal derived 'basal' layer of undifferentiated keratinocyte progenitors overlaid by the periderm, a transient barrier which is eventually shed into the amniotic fluid (30). Fetal keratinocytes express genes for keratins commonly associated with simple epithelium (31), including keratin 8, 18 and 19 (Fig. 3B). The 
expression of these keratins declines through gestation and is superseded by the expression of keratins 5 and 14 that characterize adult basal epidermis (Fig. S5B).

Force-directed graph (FDG) and partition-based approximate graph abstraction (PAGA) analyses reveal dual inferred differentiation trajectories from the stem cell genes (TP63, PPP3CA and $C A V 1 / 2)$-enriched basal cells which transition through proliferating cells into post-proliferative suprabasal cells (Fig. 3D and Table S1)(32). One arm of keratinocyte differentiation includes cells with low expression of genes associated with the formation of lamellar bodies (LB), which play a key role in late epidermal differentiation (33) (Fig. 3E). The other arm includes cells with high levels of transcripts involved in LB generation such as ABCA12, CKAP4 and CLIP1 (Fig. 3E) during suprabasal differentiation. The transcription factors $I R F 1$ and $S O X 9$, differentially expressed in our scRNA-seq analysis by keratinocytes along the two pathways relating to LBtranscript levels (Fig. S5D), mark distinct cells by immunofluorescence analysis of healthy skin (Fig. 3F). This is consistent with previous findings that human keratinocytes are differentially enriched for lamellar bodies and related proteins (34). Transcripts associated with terminal differentiation of keratinocytes (CNFN, CDSN, FLG and $I V L)$ are enriched in the suprabasal postproliferative keratinocytes at the end of the differentiation trajectories (Fig. 3E, Fig. S5C). The statistically significant differentially expressed genes using Monocle (35) across keratinocyte differentiation (Fig. S5C) recapitulate some of the previously identified genes in the literature and also in scRNA-seq analysis of murine interfollicular epidermal cells (36), including the loss of KRT5 and KRT14 and gain of IVL and FLG from basal to granular layer keratinocytes (37). The two pathways are also discernible in $\mathrm{AD}$ and psoriasis lesional skin (Fig. S5E).

Notably, the suprabasal cells expressing LB-related transcripts in healthy adult skin also coexpress genes associated with autosomal recessive congenital ichthyosis, such as $A B C A 12$, NIPAL4, SLC27A4 and TGMI (Fig. 3E). However, analysis of fetal keratinocytes showed little to no expression of these congenital ichthyosis-related genes, suggesting that disease onset at the molecular level only begins after 10 PCW (Fig. 3E). This is in keeping with the absence in fetal epidermis of a granular layer where the expression of $L O R, F L G, I V L$ and genes required for lamellar body production are located (38). Notably, AD and psoriasis lesional keratinocytes have 
altered expression of congenital ichthyosis-related genes due to keratinocyte dysfunction (Fig. 3E and Fig. S5F)(39).

We observed a cluster of post-proliferative keratinocytes expressing the chemokines CCL20, intercellular adhesion molecule $I C A M 1, T N F$ and the bradykinin receptor $B D K R B 1$ (Fig. 3A, C) in healthy adult but not in developing skin. Strikingly, these cells express higher levels of genes associated with inflammatory ichthyoses and severe atopy such as NIPAL4 and SPINK5 (Fig. 3E). Both $\mathrm{AD}$ and psoriasis lesional skin were enriched for post-proliferative keratinocytes (Fig. 3G). The proportion of post-proliferative keratinocytes expressing CCL20, ICAM and TNF are expanded in psoriasis but not AD lesional skin (Fig. 3B and G), resembling previously described CCL20-expressing keratinocytes in inflammatory skin diseases induced by Th17 cytokines and $\mathrm{TNF} \alpha(40)$. Furthermore, lesional $\mathrm{AD}$ and psoriasis skin keratinocytes express $K R T 6 A / B / C$ and KRT16, psoriasin (S100A7), calprotectin (S100A8/S100A9 heterodimer) serpins (SERPINB4, SERPINB 13) and the chemotactic factor C10orf99 (Fig S5G), previously reported to be expressed in psoriasis and $\mathrm{AD}(41-43)$.

Gene sets enriched in post-proliferative keratinocytes are dominated by immune-mediated pathways in both AD and psoriasis, including lymphocyte migration and TNF and IFN $\gamma$ signaling (Fig. 3H). Notably, the ERBB2 signaling pathway, an epidermal growth factor-like receptor tyrosine kinase, is specifically upregulated in psoriasis (Fig. 3H). Improvement in psoriasis has been noted in patients treated with anti-EGFR for underlying carcinoma (44).

\section{Transition from innate to adaptive lymphocytes during skin development}

In healthy adult skin both adaptive and innate lymphoid cells are present (Fig. 4A). T cells are predominant and consist of the three subtypes, cytotoxic (Tc) $(C D 8 A / B)$, helper (Th) $(C D 4$, CD4OLG) and regulatory (Treg) (FOXP3, TIGIT, CTLA4) cells (Fig. 4A-B). The majority of these are $\alpha ß \mathrm{~T}$ cells, with a smaller proportion of $\gamma \delta \mathrm{T}$ cells expressing TRGC2 and TRDC found within cytotoxic $\mathrm{T}$ cells in the epidermis and dermis (Fig. S6A). Innate lymphoid cells (ILCs) were identified by expression of CD161 (KLRB1) without co-expression of the delta or gamma subunit of the T cell co-receptor CD3 $(C D 3 D, C D 3 G)$ (Fig. 4B). We identified 4 clusters of innate lymphocytes, consisting of ILC1/3, ILC2, ILC1/Natural Killer (NK) and NK cells (Fig. 4A). NK 
cells expressed KLRD1, FCGR3A and the cytotoxic genes PRF1, GZMB and GNLY. ILC1/NK have overlapping feature of ILC1 and NKs, as previously described (45). Plasticity within ILC1 and ILC3 is also recognized (46) as we observed here for skin ILC1/3 (IL7R, XCL1, XCL2, TNFSRF18 and TNFSRF11). ILC2 (IL7R, PTGDR2, GATA3) has the most homogenous signature in our data and existing literature (Fig. 4B) (47).

In contrast to adult skin, the fetal skin lymphoid compartment is predominantly populated by NK and ILCs (Fig. 1D) demonstrating the dominance of innate immune cells prior to the development of the thymus, bone marrow and spleen, where T and B lymphocytes differentiate. Fetal NK cells express NKG7, GZMA, GZMB, GZMH, PRF1 and low levels of $I L 7 R$ and correlate with adult NK cells (Fig. 4B). They also express higher levels of GZMM and GZMK (Fig. 4B), suggesting that they may be functionally competent (48). Fetal skin ILCs co-express $I L 7 R, R O R C$ and KIT resembling ILC3 reported in adult skin (Fig. 4B) (49). Mast cells complete the innate immune compartment of fetal skin and co-express adult mast cell markers such as KIT, CMA1, TPSAB1 and $C P A 3$ (Fig. 1B-C, Fig. S6B).

Memory $\mathrm{T}$ cells that persist in the skin following an infection acquire properties of resident memory $\mathrm{T}$ cells, distinguishing them from central memory $\mathrm{T}$ cells found in the peripheral circulation and secondary lymphoid organs (50). We compared the gene signatures of skin and blood lymphocytes. Skin lymphocytes aligned with their blood counterparts, but express tissueresidency associated genes such as CD69 (Fig. S6C-D). Dermal T cells align more closely to blood T cells compared to epidermal T cells. (Fig. S6D).

To evaluate the impact of the cutaneous compartmental microenvironment on $\mathrm{T}$ cells, we compared the DEG between T cells in the epidermis and dermis (Fig. 4C). T cells in the epidermis upregulated genes associated with tissue residency (RGS1, PPP1R15A)(51), effector memory (CD44, ID2)(52), T cell activation (TNFRSF18)(53) and inhibition of $\mathrm{T}$ cell response (CD96, DUSP4 and TSC22D3)(54,55), in keeping with previous suggestions that resident memory T cells are poised to mount an effective immune response, but express inhibitory molecules to prevent disadvantageous responses to non-pathogenic antigens (56). In contrast dermal T cells expressed interferon stimulated genes (IFITM1, IFI6, LY6E)(57) and genes downregulated in tissue resident 
T cells (GIMAP4, GIMAP7)(51). Dermal Treg showed high expression of the central memory $\mathrm{T}$ cell marker CD62L (SELL), also observed in our CyTOF data (Fig. S3), supporting that dermal T cells are more likely to be central memory in contrast to their tissue resident epidermal counterparts.

\section{Clonal T cells in disease}

$\mathrm{T}$ cells are known to play a crucial role in the pathogenesis of $\mathrm{AD}$ and psoriasis $(58,59)$. We identified disease-specific T cells expressing cytokine genes associated with AD and psoriasis. In AD, T cells expressing IL13 and IL22 (TcIL13/IL22); and in psoriasis, T cells expressing IL17A and $I L 17 F$ (Tc17/Th17) are found in both lesional and non-lesional skin (Fig. 4D and Fig. S6E-F) but more significantly enriched in lesional skin (Fig. 4D). However, they occupy different compartments of the skin, with Tc17/Th17 cells being the dominant T cell subtype in the epidermis of lesional and non-lesional psoriasis (Fig. 4D). In contrast, TcIL13/IL22 dominate in the dermis of $\mathrm{AD}$ lesional and non-lesional skin (Fig. 4D). IL-13 is expressed in the epidermis of AD, but primarily by ILC2 (Fig. S6G), supporting the emerging and integral role of ILC2 in AD (60).

The presence and role of epidermal Tc17 cells in psoriasis pathogenesis has been previously reported $(61,62)$. TcIL13/IL22 cells in AD express amphiregulin (AREG), a member of the epidermal growth factor family and genes associated with skin tissue residency (RGS1, NR4A1, NR4A2)(51), effector T cells (ID2, PRDM1, MAP3K8)(52, 63) and T cell activation (COTL1, $M T 2 A, D U S P 2)(64,65)$ (Fig. S6E). Tc17/Th17 cells in psoriasis express genes previously reported in activated and pathogenic Th17 cells $(K L R B 1, C X C L 13$ and $R B P J)(66,67)$, generic $\mathrm{T}$ cell activation markers (JUN, TNFRSF18)(53) and acute stress proteins (HSPB1, HSPAIB, HSPA1A, $D N A J B 1, H S P E 1)($ Fig. S6E).

Significantly more cells belong to expanded Th and Treg clonotypes in healthy skin, compared to psoriasis or AD (Fig. 4E). Although the proportion of expanded Tc17/Th17 clonotypes is not significantly different between psoriasis lesional and non-lesional skin, expanded clonotypes are concentrated within the epidermis of lesional skin (Fig. S6F). 


\section{Mononuclear phagocytes in adult and developing skin}

We next focused on the composition of myeloid cells in adult and fetal skin. We observed 14 states of mononuclear phagocytes (MPs) across both dermal and epidermal layers (Fig. 5A-B). Our combined droplet scRNA-seq and Smart-seq2 datasets confirmed heterogeneity of MPs within currently used FACS-gates for these cells (Fig. S7A-B). We aligned skin MPs with blood DCs and monocytes using TransferAnchors function in Seurat (Fig. S7C) and subset-defining marker genes (68) (Fig. S7D).

Two macrophage cell states are present in healthy skin. Mac1 shows higher expression of complement transcripts $(C 1 Q B, C 1 Q C)$ and scavenger receptors $(C D 163, M A R C O)$ whereas Mac2 has higher expression of F13A1 and alternative activation and molecules related to immune suppression ( $N R 4 A 1, N R 4 A 2, K L F 4)$ (Fig. 5B and Fig. S7D), and aligned with fetal macrophages (Fig. 1E). We also identified $I L 23 A$-expressing macrophages, which we refer to as inflammatory macrophages (Fig. 5B).

We observe DC1, DC2 and Langerhans cells (LCs) in embryonic skin as early as 7 PCW, prior to bone marrow hematopoiesis but with macrophages forming the majority of skin myeloid cells in development (Fig. 1D-F). Fetal LCs are enriched for macrophage-related genes such as CD14, FCGR2A and CTSB (Fig. 5B). The embryonic origin of fetal LCs (69) and HSC origin of some adult LCs in bone marrow transplant patients (70) may explain the poor correlation between fetal and adult LCs (Fig. 1E).

\section{Phenotypic convergence of migratory dendritic cells}

In the steady state, skin DCs undergo a continual process of homeostatic maturation that is required to induce tolerance to innocuous environmental antigens (71). This is accompanied by their 
migration to skin draining lymph nodes through lymphatic vessels, a process dependent on CCR7 (72). PAGA analysis revealed three branches of differentiation: LCs, myeloid DCs (DC1 and DC2) and monocyte-derived DCs (mo-DCs) (Fig. 5C). The clusters at the convergence of these branches (moDC3, LC4 and Mig. DC) express transcripts associated with DC maturation (CD83, CCR7, LAMP3) and tolerance (CD274, IDO1) (Fig. 5B and Table S1). Amongst the top 1000 DEG for each pathway, 33\% of genes were common to all three (503 genes) and is enriched for predicted NF- $\kappa \mathrm{B}$ targets (105/503 genes predicted to be NF- $\kappa \mathrm{B}$ targets, normalized enrichment score 4.225$)(73)$ as previously reported in migratory mouse DCs (71).

Homeostatic maturation of murine dermal DC2 (74) and splenic DC1 (71) signature was enriched in LC4, moDC3 and migratory DC (mig. DC) (Fig. 5C) suggesting conservation of this signature both across species as well as DC subsets. Furthermore, acquisition of this common gene signature is associated with loss of genes conferring subset identity (Fig. 5B), as previously noted (75). We observed similar transcripts to those that define our migratory DC (CCR7, IDO1, LAMP3) within migratory DC populations in inflammation in human tonsil, ascites (76), lung cancer (77) and in our own dataset of rheumatoid arthritis synovial fluid DCs (Fig. S7E). This extends the previous observation in mice to human and generalizability of the NF- $\kappa \mathrm{B}-$ mediated maturation across species and tissues to all migratory DCs. Interestingly, fetal skin DCs and LCs lack CCR7 (Fig. 5B) and there is no equivalent of the migratory MP populations seen in adult skin (Fig. 1F). These observations alongside the immature transcriptional profile of fetal skin lymphatic endothelium suggest that migration to skin draining lymph nodes does not occur prior to $10 \mathrm{PCW}$.

\section{APCs in $A D$ and psoriasis skin}

In $\mathrm{AD}$ there is a significant increase in dermal DC2 (Fig. 5D), in the same compartment as TcIL13/IL22 (Fig. 4D). DC2 upregulate pathways related to innate immune activation including TLR2, TLR4 and Dectin-1 activation as well as IL-1 $\beta$ signaling (78) (Fig. S8A). Alongside costimulatory signaling (CD28:CD80,CD28:CD86, CD40:CD40LG), the highest predicted interactions between dermal APCs and T cells are multiple co-inhibitory (CTLA4:CD80, CTLA4:CD86, PDCD1:CD274) and anti-inflammatory (ADORA2A:ENTPD1, TGFB1:TGFBR1) interactions (Fig. S8B), consistent with a pathogenic role of these interactions in checkpoint 
inhibitor induced spongiotic dermatitis (79). Inflammatory macrophages are also relatively increased in both AD and psoriasis (Fig. 5D).

Epidermal DC2 are enriched in both psoriasis and AD skin. Highly enriched pathways are related to interferon gamma signaling and antigen presentation but also include pathways related to cellular stress, DNA damage and repair (Fig. S8C). Genes differentially expressed by epidermal DCs include the alarmins $H M G B 1, H M G N 1, I T G B 2, S 100 A 8, S 100 A 9$, which are endogenous inflammatory mediators released by damaged cells and previously reported to promote keratinocyte proliferation and cytokine production (80) (Fig. S8D).

In both $\mathrm{AD}$ and psoriasis LC1 have the highest enrichment of cell cycle genes (81) (Fig. 5E and Fig. S8E). Using FACS index data we show that LC1 are enriched within the Langerin ${ }^{+} \mathrm{CD} 1 \mathrm{a}^{\mathrm{lo}} \mathrm{CD} 11 \mathrm{c}^{\mathrm{lo}}$ gate (Fig. 5F). In contrast, the epidermal HLA-DR ${ }^{+} \mathrm{CD} 1 \mathrm{a}^{-}$Lang- $^{-}$ $\mathrm{CD} 11 \mathrm{c}^{+} \mathrm{CD} 1 \mathrm{c}^{+}$cells are predominantly mo-DCs and correspond to the recently described non-LC like epidermal cells potent at stimulating $\mathrm{T}$ cell proliferation, pro-inflammatory cytokine production, and transmission of HIV to $\mathrm{CD}^{+} \mathrm{T}$ cells $(82)$. To validate our findings, we examined LC proliferation in healthy, psoriatic and AD epidermis. Consistent with previous findings (83) we found $\mathrm{Ki} 7^{+}$Langerin $^{+}$cells increased in $\mathrm{AD}$ and psoriasis lesional skin, suggesting the existence of a LC reservoir in healthy tissue with the capacity to perpetuate skin-derived antigen presentation in AD and psoriasis (Fig. 5G).

As abnormal keratinocyte activation and differentiation feature in both AD and psoriasis, we integrated our findings of epidermal immune cells and keratinocytes to illustrate the key cellular circuits activated in AD and psoriasis (Fig. 5H-I). In psoriasis, epidermal Tc17/Th17, DC2, LC1 and mo-DC expressing IL23, appear to mediate critical interactions that culminate in keratinocyte dysfunction (Fig. 5H-I, Fig. S8F). In AD these interactions are orchestrated by IL13-expressing ILC2 and TcIL13/IL22 cells (Fig. 5H-I, Fig. S8F). DUSP10, previously shown to inhibit keratinocyte differentiation (32), is significantly downregulated in both $\mathrm{AD}$ and psoriasis, contributing to epidermal hyperplasia (Fig. 5H-I). 


\section{Discussion}

In this study we deployed scRNA-seq to resolve the cellular heterogeneity and organization of healthy human developing skin, adult skin and lesional and non-lesional skin of patients with AD and psoriasis. We reveal the dominance of innate lymphocytes during development, in contrast to T cells in adulthood and the presence of DCs and LCs as early as 7 PCW of life. We identify specialized endothelial cells that express leukocyte adhesion molecules and form dilated capillary vasculature for leukocyte trafficking and pericytes that contribute to $\mathrm{AD}$ and psoriasis pathogenesis, and keratinocyte subsets and differentiation trajectories in inflamed skin. We also identified disease-specific clonally expanded TcIL13/IL22 and Tc17/Th17 cells in AD and psoriasis skin respectively with shared TCR expression across the epidermis and dermis of lesional and non-lesional skin. We demonstrate the transcriptomic convergence of DCs and LCs into a migratory DC molecular phenotype reflecting homeostatic migration of skin APC into lymphatic vessels. Collectively, our findings demonstrate micro-anatomically organized immunological niches within healthy human skin which become reconfigured in $\mathrm{AD}$ and psoriasis.

Two models for keratinocyte differentiation have been proposed: random division of a single population of stem cells (stochastic) or hierarchical differentiation of stem cells or stem cells and transit-amplifying cells prior to differentiation (hierarchical)(84). Our analysis shows that keratinocyte differentiation trajectory involves two pathways present in healthy and inflamed skin. This is consistent with keratinocyte differentiation according to both the stochastic and hierarchical models $(85,86)$. It is notable that $I R F 2$, which is expressed at a higher level in the second pathway involving lamellar body keratinocytes, was reported as a critical regulator of keratinocyte lamellar body proteins in mice (87). Although in fetal skin a periderm layer provides protection in an aquatic environment (88), lamellar body-related genes are not prominent and post-proliferative inflammatory keratinocytes are absent. The post-proliferative inflammatory keratinocytes expanded in psoriasis lesional skin likely correspond to previously described CCL20-secreting keratinocytes following inflammatory perturbation (40) and may be relevant to the Koebner phenomenon in psoriasis.

The specialized vascular endothelial cells (VE3) that form distended capillaries in the dermis morphologically resemble high endothelial venules (HEVs) in lymphoid organs. HEVs mediate 
leukocyte entry into lymph nodes for immune surveillance and express many of the same leukocyte adhesion and chemokine molecules as VE3 such as CD34, ICAM1 and IL33 (89, 90). VE3 and pericyte2 in $\mathrm{AD}$ and psoriasis appear to be actively involved in leukocyte recruitment and present additional therapeutic targets. Notably, fetal fibroblasts, pericytes and VE cells are aligned to adult counterparts (Fb2, Pericyte2 and VE3) that are relatively expanded in both AD and psoriasis. This suggests that tissue modelling during development may be co-opted in tissue re-modeling in disease.

The striking presence of innate lymphoid cells such as NK cells, DCs and LCs as early as 7 PCW in a sterile in utero environment raises the question of their raison d'être during early development when afferent lymphatics are poorly developed and T cells are absent. NKs and DCs during early development may play a critical role in tissue genesis and modelling, potentially through interaction with other skin cells via HLA-E, which is known to inhibit killing by NK cells under some circumstances (91). The precise molecular dissection of how NK and DCs contribute to tissue development merits further investigation in future studies. Differences in the embryonic or fetal and adult microbiomes in human tissues have been previously reported and may influence the immune composition of the skin as a barrier tissue $(92,93)$. We identify for the first time that mo-DCs are abundant in healthy human skin. Future work is required to confirm whether skin mo-DCs are blood monocyte- or DC3-derived. The presence of homeostatic maturation and migration of DCs in human skin were previously underestimated as migrating cells downregulate canonical DC and LC markers e.g. CD1a, CD1c and Langerin.

In summary, our comprehensive atlas of human skin reveals key circuits involved in AD and psoriasis pathogenesis and provides a foundational resource on the dynamic cellular topology that evolves during development, adulthood and inflammatory skin disease. 


\section{References:}

1. S.W. Kashem, M. Haniffa, D. Kaplan. Antigen presenting cells in the skin. Annu. Rev. Immunol. 35, 469-499 (2017).

2. F. Lafouresse, J. R. Groom, A Task Force Against Local Inflammation and Cancer: Lymphocyte Trafficking to and Within the Skin. Front. Immunol. 9, 2454 (2018).

3. K. M. HALPRIN, EPIDERMAL “TURNOVER TIME”-A RE-EXAMINATION. Br. $J$. Dermatol. 86, 14-19 (1972).

4. K. Clayton, A. F. Vallejo, J. Davies, S. Sirvent, M. E. Polak, Langerhans Cells_-Programmed by the Epidermis. Front. Immunol. 8, 1676 (2017).

5. T. Kobayashi, S. Naik, K. Nagao, Choreographing Immunity in the Skin Epithelial Barrier. Immunity. 50, 552-565 (2019).

6. M. P. Schön, Adaptive and Innate Immunity in Psoriasis and Other Inflammatory Disorders. Front. Immunol. 10, 1764 (2019).

7. E. Guttman-Yassky, J. G. Krueger, Atopic dermatitis and psoriasis: two different immune diseases or one spectrum? Curr. Opin. Immunol. 48, 68-73 (2017).

8. J. B. Cheng, A. J. Sedgewick, A. I. Finnegan, P. Harirchian, J. Lee, S. Kwon, M. S. Fassett, J. Golovato, M. Gray, R. Ghadially, W. Liao, B. E. Perez White, T. M. Mauro, T. Mully, E. A. Kim, H. Sbitany, I. M. Neuhaus, R. C. Grekin, S. S. Yu, J. W. Gray, E. Purdom, R. Paus, C. J. Vaske, S. C. Benz, J. S. Song, R. J. Cho, Transcriptional Programming of Normal and Inflamed Human Epidermis at Single-Cell Resolution. Cell Rep. 25, 871-883 (2018).

9. C. Philippeos, S. B. Telerman, B. Oulès, A. O. Pisco, T. J. Shaw, R. Elgueta, G. Lombardi, R. R. Driskell, M. Soldin, M. D. Lynch, F. M. Watt, Spatial and Single-Cell Transcriptional Profiling Identifies Functionally Distinct Human Dermal Fibroblast Subpopulations. J. Invest. Dermatol. 138, 811-825 (2018).

10. K. Polański, M. D. Young, Z. Miao, K. B. Meyer, S. A. Teichmann, J.-E. Park, BBKNN: fast batch alignment of single cell transcriptomes. Bioinformatics (2019), doi:10.1093/bioinformatics/btz625. 
11. F. A. Wolf, P. Angerer, F. J. Theis, SCANPY: large-scale single-cell gene expression data analysis. Genome Biol. 19, 15 (2018).

12. D.-M. Popescu, R. A. Botting, E. Stephenson, K. Green, S. Webb, L. Jardine, E. F. Calderbank, K. Polanski, I. Goh, M. Efremova, M. Acres, D. Maunder, P. Vegh, Y. Gitton, J.E. Park, R. Vento-Tormo, Z. Miao, D. Dixon, R. Rowell, D. McDonald, J. Fletcher, E. Poyner, G. Reynolds, M. Mather, C. Moldovan, L. Mamanova, F. Greig, M. D. Young, K. B. Meyer, S. Lisgo, J. Bacardit, A. Fuller, B. Millar, B. Innes, S. Lindsay, M. J. T. Stubbington, M. S. Kowalczyk, B. Li, O. Ashenberg, M. Tabaka, D. Dionne, T. L. Tickle, M. Slyper, O. Rozenblatt-Rosen, A. Filby, P. Carey, A.-C. Villani, A. Roy, A. Regev, A. Chédotal, I. Roberts, B. Göttgens, S. Behjati, E. Laurenti, S. A. Teichmann, M. Haniffa, Decoding human fetal liver haematopoiesis. Nature. 574, 365-371 (2019).

13. T. Stuart, A. Butler, P. Hoffman, C. Hafemeister, E. Papalexi, W. M. Mauck, Y. Hao, M. Stoeckius, P. Smibert, R. Satija, Comprehensive Integration of Single-Cell Data. Cell. 177, 1888-1902.e21 (2019).

14. G. X. Y. Zheng, J. M. Terry, P. Belgrader, P. Ryvkin, Z. W. Bent, R. Wilson, S. B. Ziraldo, T. D. Wheeler, G. P. McDermott, J. Zhu, M. T. Gregory, J. Shuga, L. Montesclaros, J. G. Underwood, D. A. Masquelier, S. Y. Nishimura, M. Schnall-Levin, P. W. Wyatt, C. M. Hindson, R. Bharadwaj, A. Wong, K. D. Ness, L. W. Beppu, H. J. Deeg, C. McFarland, K. R. Loeb, W. J. Valente, N. G. Ericson, E. A. Stevens, J. P. Radich, T. S. Mikkelsen, B. J. Hindson, J. H. Bielas, Massively parallel digital transcriptional profiling of single cells. Nat. Commun. 8, 14049 (2017).

15. S. A. N. D’Mello, G. J. Finlay, B. C. Baguley, M. E. Askarian-Amiri, Signaling Pathways in Melanogenesis. Int. J. Mol. Sci. 17, 1144 (2016).

16. T. Tabib, C. Morse, T. Wang, W. Chen, R. Lafyatis, SFRP2/DPP4 and FMO1/LSP1 Define Major Fibroblast Populations in Human Skin. J. Invest. Dermatol. 138, 802-810 (2018).

17. M. K. Lichtman, M. Otero-Vinas, V. Falanga, Transforming growth factor beta (TGF- $\beta$ ) isoforms in wound healing and fibrosis. Wound Repair Regen. 24, 215-222 (2016).

18. X.-N. Wang, N. McGovern, M. Gunawan, C. Richardson, M. Windebank, T.-W. Siah, H.-Y. Lim, K. Fink, J. L. Yao Li, L. G. Ng, F. Ginhoux, V. Angeli, M. Collin, M. Haniffa, A threedimensional atlas of human dermal leukocytes, lymphatics, and blood vessels. J. Invest.

Dermatol. 134, 965-974 (2014). 
19. T. Tammela, K. Alitalo, Lymphangiogenesis: Molecular Mechanisms and Future Promise. Cell. 140, 460-476 (2010).

20. A. Thiriot, C. Perdomo, G. Cheng, I. Novitzky-Basso, S. McArdle, J. K. Kishimoto, O. Barreiro, I. Mazo, R. Triboulet, K. Ley, A. Rot, U. H. von Andrian, Differential DARC/ACKR1 expression distinguishes venular from non-venular endothelial cells in murine tissues. BMC Biol. 15, 45-45 (2017).

21. I. Tirosh, B. Izar, S. M. Prakadan, M. H. Wadsworth 2nd, D. Treacy, J. J. Trombetta, A. Rotem, C. Rodman, C. Lian, G. Murphy, M. Fallahi-Sichani, K. Dutton-Regester, J.-R. Lin, O. Cohen, P. Shah, D. Lu, A. S. Genshaft, T. K. Hughes, C. G. K. Ziegler, S. W. Kazer, A. Gaillard, K. E. Kolb, A.-C. Villani, C. M. Johannessen, A. Y. Andreev, E. M. Van Allen, M. Bertagnolli, P. K. Sorger, R. J. Sullivan, K. T. Flaherty, D. T. Frederick, J. Jané-Valbuena, C. H. Yoon, O. Rozenblatt-Rosen, A. K. Shalek, A. Regev, L. A. Garraway, Dissecting the multicellular ecosystem of metastatic melanoma by single-cell RNA-seq. Science. 352, 189196 (2016).

22. H. Zhang, A. Kouadio, D. Cartledge, A. K. Godwin, Role of gamma-synuclein in microtubule regulation. Exp. Cell Res. 317, 1330-1339 (2011).

23. A. Surguchov, R. E. Palazzo, I. Surgucheva, Gamma synuclein: Subcellular localization in neuronal and non-neuronal cells and effect on signal transduction. Cell Motil. 49, 218-228 (2001).

24. R. Vento-Tormo, M. Efremova, R. A. Botting, M. Y. Turco, M. Vento-Tormo, K. B. Meyer, J.-E. Park, E. Stephenson, K. Polański, A. Goncalves, L. Gardner, S. Holmqvist, J. Henriksson, A. Zou, A. M. Sharkey, B. Millar, B. Innes, L. Wood, A. Wilbrey-Clark, R. P. Payne, M. A. Ivarsson, S. Lisgo, A. Filby, D. H. Rowitch, J. N. Bulmer, G. J. Wright, M. J. T. Stubbington, M. Haniffa, A. Moffett, S. A. Teichmann, Single-cell reconstruction of the early maternal-fetal interface in humans. Nature. 563, 347-353 (2018).

25. M. Efremova, M. Vento-Tormo, S. A. Teichmann, R. Vento-Tormo, CellPhoneDB v2.0: Inferring cell-cell communication from combined expression of multi-subunit receptor-ligand complexes. bioRxiv, 680926 (2019).

26. C. Schuster, M. Mildner, A. Botta, L. Nemec, R. Rogojanu, L. Beer, C. Fiala, W. Eppel, W. Bauer, P. Petzelbauer, A. Elbe-Bürger, Development of Blood and Lymphatic Endothelial Cells in Embryonic and Fetal Human Skin. Am. J. Pathol. 185, 2563-2574 (2015). 
27. S. Rodius, G. Indra, C. Thibault, V. Pfister, E. Georges-Labouesse, Loss of $\alpha 6$ integrins in keratinocytes leads to an increase in TGF $\beta$ and AP1 signaling and in expression of differentiation genes. J. Cell. Physiol. 212, 439-449 (2007).

28. G. Livshits, A. Kobielak, E. Fuchs, Governing epidermal homeostasis by coupling cell-cell adhesion to integrin and growth factor signaling, proliferation, and apoptosis. Proc. Natl. Acad. Sci. U. S. A. 109, 4886-4891 (2012).

29. N. Otberg, H. Richter, H. Schaefer, U. Blume-Peytavi, W. Sterry, J. Lademann, Variations of Hair Follicle Size and Distribution in Different Body Sites. J. Invest. Dermatol. 122, 14-19 (2004).

30. T. Agorastos, T. Bar, E. I. Grussendorf, B. Liedtke, G. Lamberti, ["Ultrastructural aspects of amniotic-fluid cells" A. non-vital cells. iii. large squamous cells (author's transl)]. $Z$. Geburtshilfe Perinatol. 185, 231-235 (1981).

31. M. B. Omary, N.-O. Ku, P. Strnad, S. Hanada, Toward unraveling the complexity of simple epithelial keratins in human disease. J. Clin. Invest. 119, 1794-1805 (2009).

32. A. Mishra, B. Oulès, A. O. Pisco, T. Ly, K. Liakath-Ali, G. Walko, P. Viswanathan, M. Tihy, J. Nijjher, S.-J. Dunn, A. I. Lamond, F. M. Watt, A protein phosphatase network controls the temporal and spatial dynamics of differentiation commitment in human epidermis. eLife. 6 , e27356 (2017).

33. K. R. Feingold, Lamellar Bodies: The Key to Cutaneous Barrier Function. J. Invest. Dermatol. 132, 1951-1953 (2012).

34. A.-A. Raymond, A. G. de Peredo, A. Stella, A. Ishida-Yamamoto, D. Bouyssie, G. Serre, B. Monsarrat, M. Simon, Lamellar Bodies of Human Epidermis. Mol. Amp Cell. Proteomics. 7, 2151 (2008).

35. C. Trapnell, D. Cacchiarelli, J. Grimsby, P. Pokharel, S. Li, M. Morse, N. J. Lennon, K. J. Livak, T. S. Mikkelsen, J. L. Rinn, The dynamics and regulators of cell fate decisions are revealed by pseudotemporal ordering of single cells. Nat. Biotechnol. 32, 381-386 (2014).

36. S. Joost, A. Zeisel, T. Jacob, X. Sun, G. La Manno, P. Lonnerberg, S. Linnarsson, M. Kasper, Single-Cell Transcriptomics Reveals that Differentiation and Spatial Signatures Shape Epidermal and Hair Follicle Heterogeneity. Cell Syst. 3, 221-237.e9 (2016). 
37. M. Degen, A. Wiederkehr, G. C. La Scala, C. Carmann, I. Schnyder, C. Katsaros, Keratinocytes Isolated From Individual Cleft Lip/Palate Patients Display Variations in Their Differentiation Potential in vitro. Front. Physiol. 9, 1703-1703 (2018).

38. S.-C. Lee, J.-B. Lee, J.-P. Kook, J.-J. Seo, Y. P. Kim, K.-I. Nam, S.-S. Park, Expression of Differentiation Markers During Fetal Skin Development in Humans: Immunohistochemical Studies on the Precursor Proteins Forming the Cornified Cell Envelope. J. Invest. Dermatol. 112, 882-886 (1999).

39. M. Kelleher, A. Dunn-Galvin, J. O. Hourihane, D. Murray, L. E. Campbell, W. H. I. McLean, A. D. Irvine, Skin barrier dysfunction measured by transepidermal water loss at 2 days and 2 months predates and predicts atopic dermatitis at 1 year. J. Allergy Clin. Immunol. 135, 9305.e1 (2015).

40. E. G. Harper, C. Guo, H. Rizzo, J. V. Lillis, S. E. Kurtz, I. Skorcheva, D. Purdy, E. Fitch, M. Iordanov, A. Blauvelt, Th17 cytokines stimulate CCL20 expression in keratinocytes in vitro and in vivo: implications for psoriasis pathogenesis. J. Invest. Dermatol. 129, 2175-2183 (2009).

41. H. B. Schonthaler, J. Guinea-Viniegra, S. K. Wculek, I. Ruppen, P. Ximenez-Embun, A. Guio-Carrion, R. Navarro, N. Hogg, K. Ashman, E. F. Wagner, S100A8-S100A9 protein complex mediates psoriasis by regulating the expression of complement factor C3. Immunity. 39, 1171-1181 (2013).

42. U. Sivaprasad, K. G. Kinker, M. B. Ericksen, M. Lindsey, A. M. Gibson, S. A. Bass, N. S. Hershey, J. Deng, M. Medvedovic, G. K. Khurana Hershey, SERPINB3/B4 contributes to early inflammation and barrier dysfunction in an experimental murine model of atopic dermatitis. J. Invest. Dermatol. 135, 160-169 (2015).

43. J. Zhu, Z. Wang, F. Chen, Association of Key Genes and Pathways with Atopic Dermatitis by Bioinformatics Analysis. Med. Sci. Monit. Int. Med. J. Exp. Clin. Res. 25, 4353-4361 (2019).

44. S. Wang, Z. Zhang, H. Peng, K. Zeng, Recent advances on the roles of epidermal growth factor receptor in psoriasis. Am. J. Transl. Res. 11, 520-528 (2019).

45. H. Spits, J. H. Bernink, L. Lanier, NK cells and type 1 innate lymphoid cells: partners in host defense. Nat. Immunol. 17, 758-764 (2016).

46. J. H. Bernink, L. Krabbendam, K. Germar, E. de Jong, K. Gronke, M. Kofoed-Nielsen, J. M. Munneke, M. D. Hazenberg, J. Villaudy, C. J. Buskens, W. A. Bemelman, A. Diefenbach, B. 
Blom, H. Spits, Interleukin-12 and -23 Control Plasticity of CD127+ Group 1 and Group 3 Innate Lymphoid Cells in the Intestinal Lamina Propria. Immunity. 43, 146-160 (2015).

47. M. L. Robinette, A. Fuchs, V. S. Cortez, J. S. Lee, Y. Wang, S. K. Durum, S. Gilfillan, M. Colonna, L. Shaw, B. Yu, A. Goldrath, S. Mostafavi, A. Regev, E. Y. Kim, D. F. Dwyer, M. B. Brenner, K. F. Austen, A. Rhoads, D. Moodley, H. Yoshida, D. Mathis, C. Benoist, T. Nabekura, V. Lam, L. L. Lanier, B. Brown, M. Merad, V. Cremasco, S. Turley, P. Monach, M. L. Dustin, Y. Li, S. A. Shinton, R. R. Hardy, T. Shay, Y. Qi, K. Sylvia, J. Kang, K. Fairfax, G. J. Randolph, M. L. Robinette, A. Fuchs, M. Colonna, the Immunological Genome Consortium, Transcriptional programs define molecular characteristics of innate lymphoid cell classes and subsets. Nat. Immunol. 16, 306-317 (2015).

48. L. S. Angelo, L. H. Bimler, R. Nikzad, K. Aviles-Padilla, S. Paust, CXCR6(+) NK Cells in Human Fetal Liver and Spleen Possess Unique Phenotypic and Functional Capabilities. Front. Immunol. 10, 469-469 (2019).

49. M.-C. Brüggen, W. M. Bauer, B. Reininger, E. Clim, C. Captarencu, G. E. Steiner, P. M. Brunner, B. Meier, L. E. French, G. Stingl, In Situ Mapping of Innate Lymphoid Cells in Human Skin: Evidence for Remarkable Differences between Normal and Inflamed Skin. $J$. Invest. Dermatol. 136, 2396-2405 (2016).

50. S. N. Mueller, L. K. Mackay, Tissue-resident memory T cells: local specialists in immune defence. Nat. Rev. Immunol. 16, 79-89 (2016).

51. J. Li, M. Olshansky, F. R. Carbone, J. Z. Ma, Transcriptional Analysis of T Cells Resident in Human Skin. PLOS ONE. 11, e0148351 (2016).

52. K. D. Omilusik, M. S. Nadjsombati, L. A. Shaw, B. Yu, J. J. Milner, A. W. Goldrath, Sustained Id 2 regulation of E proteins is required for terminal differentiation of effector CD8+ T cells. J. Exp. Med. 215, 773-783 (2018).

53. E. M. Esparza, R. H. Arch, Glucocorticoid-Induced TNF Receptor Functions as a Costimulatory Receptor That Promotes Survival in Early Phases of T Cell Activation. $J$. Immunol. 174, 7869 (2005).

54. K. Stanko, C. Iwert, C. Appelt, K. Vogt, J. Schumann, F. J. Strunk, S. Ahrlich, S. Schlickeiser, C. Romagnani, K. Jürchott, C. Meisel, G. Willimsky, A. A. Kühl, B. Sawitzki, CD96 expression determines the inflammatory potential of IL-9-producing Th9 cells. Proc. Natl. Acad. Sci. 115, E2940 (2018). 
55. C.-Y. Huang, Y.-C. Lin, W.-Y. Hsiao, F.-H. Liao, P.-Y. Huang, T.-H. Tan, DUSP4 deficiency enhances CD25 expression and CD4+ T-cell proliferation without impeding T-cell development. Eur. J. Immunol. 42, 476-488 (2012).

56. B. V. Kumar, W. Ma, M. Miron, T. Granot, R. S. Guyer, D. J. Carpenter, T. Senda, X. Sun, S.-H. Ho, H. Lerner, A. L. Friedman, Y. Shen, D. L. Farber, Human Tissue-Resident Memory T Cells Are Defined by Core Transcriptional and Functional Signatures in Lymphoid and Mucosal Sites. Cell Rep. 20, 2921-2934 (2017).

57. J. W. Schoggins, C. M. Rice, Interferon-stimulated genes and their antiviral effector functions. Innate ImmunityAntivirals Resist. Viruses. 1, 519-525 (2011).

58. T. Biedermann, Y. Skabytska, S. Kaesler, T. Volz, Regulation of T Cell Immunity in Atopic Dermatitis by Microbes: The Yin and Yang of Cutaneous Inflammation. Front. Immunol. 6, 353-353 (2015).

59. Y. Cai, C. Fleming, J. Yan, New insights of T cells in the pathogenesis of psoriasis. Cell. Mol. Immunol. 9, 302-309 (2012).

60. M. Salimi, J. L. Barlow, S. P. Saunders, L. Xue, D. Gutowska-Owsiak, X. Wang, L.-C. Huang, D. Johnson, S. T. Scanlon, A. N. J. McKenzie, P. G. Fallon, G. S. Ogg, A role for IL25 and IL-33-driven type-2 innate lymphoid cells in atopic dermatitis. J. Exp. Med. 210, 2939-2950 (2013).

61. I. Kryczek, A. T. Bruce, J. E. Gudjonsson, A. Johnston, A. Aphale, L. Vatan, W. Szeliga, Y. Wang, Y. Liu, T. H. Welling, J. T. Elder, W. Zou, Induction of IL-17 $7^{+}$T Cell Trafficking and Development by IFN- $\gamma$ : Mechanism and Pathological Relevance in Psoriasis. J. Immunol. 181, 4733 (2008).

62. P. Di Meglio, F. Villanova, A. A. Navarini, A. Mylonas, I. Tosi, F. O. Nestle, C. Conrad, Targeting CD8+ T cells prevents psoriasis development. J. Allergy Clin. Immunol. 138, 274276.e6 (2016).

63. F. Z. Chowdhury, L. D. Estrada, S. Murray, J. Forman, J. D. Farrar, Pharmacological Inhibition of TPL2/MAP3K8 Blocks Human Cytotoxic T Lymphocyte Effector Functions. PLOS ONE. 9, e92187 (2014).

64. J. Kim, M. J. Shapiro, A. O. Bamidele, P. Gurel, P. Thapa, H. N. Higgs, K. E. Hedin, V. S. Shapiro, D. D. Billadeau, Coactosin-Like 1 Antagonizes Cofilin to Promote Lamellipodial Protrusion at the Immune Synapse. PLOS ONE. 9, e85090 (2014). 
65. W. Wei, Y. Jiao, A. Postlethwaite, J. M. Stuart, Y. Wang, D. Sun, W. Gu, Dual-specificity phosphatases 2: surprising positive effect at the molecular level and a potential biomarker of diseases. Genes Immun. 14, 1-6 (2013).

66. R. Ramesh, L. Kozhaya, K. McKevitt, I. M. Djuretic, T. J. Carlson, M. A. Quintero, J. L. McCauley, M. T. Abreu, D. Unutmaz, M. S. Sundrud, Pro-inflammatory human Th17 cells selectively express P-glycoprotein and are refractory to glucocorticoids. J. Exp. Med. 211, 89104 (2014).

67. G. Meyer zu Horste, C. Wu, C. Wang, L. Cong, M. Pawlak, Y. Lee, W. Elyaman, S. Xiao, A. Regev, V. K. Kuchroo, RBPJ Controls Development of Pathogenic Th17 Cells by Regulating IL-23 Receptor Expression. Cell Rep. 16, 392-404 (2016).

68. A.-C. Villani, R. Satija, G. Reynolds, S. Sarkizova, K. Shekhar, J. Fletcher, M. Griesbeck, A. Butler, S. Zheng, S. Lazo, L. Jardine, D. Dixon, E. Stephenson, E. Nilsson, I. Grundberg, D. McDonald, A. Filby, W. Li, P. L. De Jager, O. Rozenblatt-Rosen, A. A. Lane, M. Haniffa, A. Regev, N. Hacohen, Single-cell RNA-seq reveals new types of human blood dendritic cells, monocytes, and progenitors. Science. 356 (2017), doi:10.1126/science.aah4573.

69. G. Hoeffel, Y. Wang, M. Greter, P. See, P. Teo, B. Malleret, M. Leboeuf, D. Low, G. Oller, F. Almeida, S. H. Y. Choy, M. Grisotto, L. Renia, S. J. Conway, E. R. Stanley, J. K. Y. Chan, L. G. Ng, I. M. Samokhvalov, M. Merad, F. Ginhoux, Adult Langerhans cells derive predominantly from embryonic fetal liver monocytes with a minor contribution of yolk sacderived macrophages. J. Exp. Med. 209, 1167-1181 (2012).

70. M. P. Collin, D. N. J. Hart, G. H. Jackson, G. Cook, J. Cavet, S. Mackinnon, P. G. Middleton, A. M. Dickinson, The fate of human Langerhans cells in hematopoietic stem cell transplantation. J. Exp. Med. 203, 27-33 (2006).

71. L. Ardouin, H. Luche, R. Chelbi, S. Carpentier, A. Shawket, F. Montanana Sanchis, C. Santa Maria, P. Grenot, Y. Alexandre, C. Grégoire, A. Fries, T.-P. Vu Manh, S. Tamoutounour, K. Crozat, E. Tomasello, A. Jorquera, E. Fossum, B. Bogen, H. Azukizawa, M. Bajenoff, S. Henri, M. Dalod, B. Malissen, Broad and Largely Concordant Molecular Changes Characterize Tolerogenic and Immunogenic Dendritic Cell Maturation in Thymus and Periphery. Immunity. 45, 305-318 (2016).

72. N. McGovern, A. Schlitzer, M. Gunawan, L. Jardine, A. Shin, E. Poyner, K. Green, R. Dickinson, X.-N. Wang, D. Low, K. Best, S. Covins, P. Milne, S. Pagan, K. Aljefri, M. 
Windebank, D. Miranda-Saavedra, A. Larbi, P. S. Wasan, K. Duan, M. Poidinger, V. Bigley, F. Ginhoux, M. Collin, M. Haniffa, Human dermal CD14 ${ }^{+}$cells are a transient population of monocyte-derived macrophages. Immunity. 41, 465-477 (2014).

73. R. Janky, A. Verfaillie, H. Imrichová, B. Van de Sande, L. Standaert, V. Christiaens, G. Hulselmans, K. Herten, M. Naval Sanchez, D. Potier, D. Svetlichnyy, Z. Kalender Atak, M. Fiers, J.-C. Marine, S. Aerts, iRegulon: From a Gene List to a Gene Regulatory Network Using Large Motif and Track Collections. PLOS Comput. Biol. 10, e1003731 (2014).

74. S. Tamoutounour, M. Guilliams, F. Montanana Sanchis, H. Liu, D. Terhorst, C. Malosse, E. Pollet, L. Ardouin, H. Luche, C. Sanchez, M. Dalod, B. Malissen, S. Henri, Origins and Functional Specialization of Macrophages and of Conventional and Monocyte-Derived Dendritic Cells in Mouse Skin. Immunity. 39, 925-938 (2013).

75. T.-P. Vu Manh, N. Bertho, A. Hosmalin, I. Schwartz-Cornil, M. Dalod, Investigating Evolutionary Conservation of Dendritic Cell Subset Identity and Functions. Front. Immunol. 6, 260-260 (2015).

76. T.-L. Tang-Huau, P. Gueguen, C. Goudot, M. Durand, M. Bohec, S. Baulande, B. Pasquier, S. Amigorena, E. Segura, Human in vivo-generated monocyte-derived dendritic cells and macrophages cross-present antigens through a vacuolar pathway. Nat. Commun. 9, 25702570 (2018).

77. R. Zilionis, C. Engblom, C. Pfirschke, V. Savova, D. Zemmour, H. D. Saatcioglu, I. Krishnan, G. Maroni, C. V. Meyerovitz, C. M. Kerwin, S. Choi, W. G. Richards, A. De Rienzo, D. G. Tenen, R. Bueno, E. Levantini, M. J. Pittet, A. M. Klein, Single-Cell Transcriptomics of Human and Mouse Lung Cancers Reveals Conserved Myeloid Populations across Individuals and Species. Immunity. 50, 1317-1334.e10 (2019).

78. G. Yu, L.-G. Wang, Y. Han, Q.-Y. He, clusterProfiler: an R package for comparing biological themes among gene clusters. Omics J. Integr. Biol. 16, 284-287 (2012).

79. J. A. Marin-Acevedo, R. M. Chirila, R. S. Dronca, Immune Checkpoint Inhibitor Toxicities. Mayo Clin. Proc. 94, 1321-1329 (2019).

80. M. P. Schön, L. Erpenbeck, The Interleukin-23/Interleukin-17 Axis Links Adaptive and Innate Immunity in Psoriasis. Front. Immunol. 9, 1323 (2018).

81. M. S. Kowalczyk, I. Tirosh, D. Heckl, T. N. Rao, A. Dixit, B. J. Haas, R. K. Schneider, A. J. Wagers, B. L. Ebert, A. Regev, Single-cell RNA-seq reveals changes in cell cycle and 
differentiation programs upon aging of hematopoietic stem cells. Genome Res. 25, 1860-1872 (2015).

82. K. M. Bertram, R. A. Botting, H. Baharlou, J. W. Rhodes, H. Rana, J. D. Graham, E. Patrick, J. Fletcher, T. M. Plasto, N. R. Truong, C. Royle, C. M. Doyle, O. Tong, N. Nasr, L. Barnouti, M. P. Kohout, A. J. Brooks, M. P. Wines, P. Haertsch, J. Lim, M. P. Gosselink, G. Ctercteko, J. D. Estes, M. J. Churchill, P. U. Cameron, E. Hunter, M. A. Haniffa, A. L. Cunningham, A. N. Harman, Identification of HIV transmitting CD11c+ human epidermal dendritic cells. Nat. Commun. 10, 2759 (2019).

83. L. Chorro, A. Sarde, M. Li, K. J. Woollard, P. Chambon, B. Malissen, A. Kissenpfennig, J.-B. Barbaroux, R. Groves, F. Geissmann, Langerhans cell (LC) proliferation mediates neonatal development, homeostasis, and inflammation-associated expansion of the epidermal LC network. J. Exp. Med. 206, 3089-3100 (2009).

84. P. H. Jones, B. D. Simons, F. M. Watt, Sic Transit Gloria: Farewell to the Epidermal Transit Amplifying Cell? Cell Stem Cell. 1, 371-381 (2007).

85. K. B. Jensen, F. M. Watt, Single-cell expression profiling of human epidermal stem and transit-amplifying cells: Lrig1 is a regulator of stem cell quiescence. Proc. Natl. Acad. Sci. U. S. A. 103, 11958-11963 (2006).

86. D. W. M. Tan, K. B. Jensen, M. W. B. Trotter, J. T. Connelly, S. Broad, F. M. Watt, Singlecell gene expression profiling reveals functional heterogeneity of undifferentiated human epidermal cells. Development. 140, 1433 (2013).

87. Y. Kamata, M. Yamamoto, F. Kawakami, R. Tsuboi, A. Takeda, K. Ishihara, T. Hibino, Bleomycin hydrolase is regulated biphasically in a differentiation- and cytokine-dependent manner: relevance to atopic dermatitis. J. Biol. Chem. 286, 8204-8212 (2011).

88. R. J. Richardson, N. L. Hammond, P. A. Coulombe, C. Saloranta, H. O. Nousiainen, R. Salonen, A. Berry, N. Hanley, D. Headon, R. Karikoski, M. J. Dixon, Periderm prevents pathological epithelial adhesions during embryogenesis. J. Clin. Invest. 124, 3891-3900 (2014).

89. Pollheimer Jürgen, Bodin Johanna, Sundnes Olav, Edelmann Reidunn J., Skånland Sigrid S., Sponheim Jon, Brox Mari Johanna, Sundlisæter Eirik, Loos Tamara, Vatn Morten, Kasprzycka Monika, Wang Junbai, Küchler Axel M., Taskén Kjetil, Haraldsen Guttorm, Hol 
Johanna, Interleukin-33 Drives a Proinflammatory Endothelial Activation That Selectively Targets Nonquiescent Cells. Arterioscler. Thromb. Vasc. Biol. 33, e47-e55 (2013).

90. K. Veerman, C. Tardiveau, F. Martins, J. Coudert, J.-P. Girard, Single-Cell Analysis Reveals Heterogeneity of High Endothelial Venules and Different Regulation of Genes Controlling Lymphocyte Entry to Lymph Nodes. Cell Rep. 26, 3116-3131.e5 (2019).

91. S. Sugita, K. Makabe, Y. Iwasaki, S. Fujii, M. Takahashi, Natural Killer Cell Inhibition by HLA-E Molecules on Induced Pluripotent Stem Cell-Derived Retinal Pigment Epithelial CellsSuppression of NK Cells by iPS-RPE Cells. Invest. Ophthalmol. Vis. Sci. 59, 1719-1731 (2018).

92. Y. Belkaid, S. Naik. Compartmentalized and systemic control of tissue immunity by commensals. Nat Immunol. 7, 646-53 (2013).

93. M. G. Dominguez-Bello, F. Godoy-Vitorino, R. Knight, M. J. Blaser, Role of the microbiome in human development. Gut. 68, 1108 (2019).

\section{Acknowledgments:}

We thank the Newcastle University Flow Cytometry Core Facility, Bioimaging Core Facility, Genomics Core Facility and NUIT for technical assistance, School of Computing for access to the High-Performance Computing Cluster, Newcastle Molecular Pathology Node Proximity Lab and Alison Farnworth for clinical liaison. The human embryonic and fetal material was provided by the Joint MRC / Wellcome (MR/R006237/1) Human Developmental Biology Resource (www.hdbr.org).

\section{Funding}

We acknowledge funding from the Wellcome Human Cell Atlas Strategic Science Support (WT211276/Z/18/Z); M.H. is funded by Wellcome (WT107931/Z/15/Z), The Lister Institute for Preventive Medicine and NIHR and Newcastle-Biomedical Research Centre; S.A.T. is funded by Wellcome (WT206194), ERC Consolidator and EU MRG-Grammar awards. NJR is funded by NIHR, Newcastle MRC/EPSRC Molecular Pathology Node and Newcastle NIHR Medtech Diagnostic Co-operative. E.P is funded by a Wellcome 4ward-North Clinical Training Fellowship. 
bioRxiv preprint doi: https://doi.org/10.1101/2020.11.05.369363; this version posted November 5, 2020. The copyright holder for this preprint (which was not certified by peer review) is the author/funder. All rights reserved. No reuse allowed without permission.

\section{Figure 1. Deconstructing human skin}

A

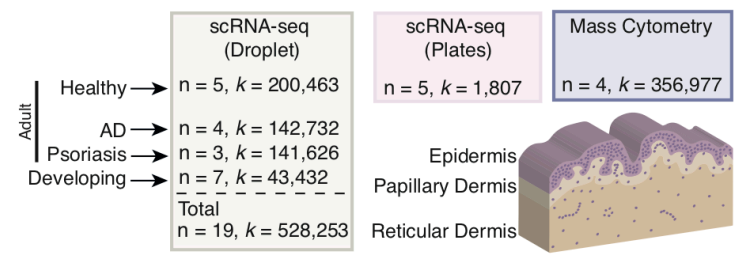

C
B

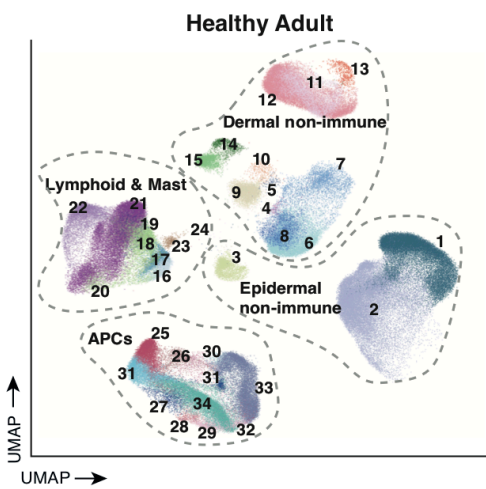

Epidermal non-immune Lymphoid \& Mast 1 Pre-prolif. KC 16 LLC1/3 2 Post. prolif. KC $17 . \mathrm{LC} 1 / \mathrm{NK}$ 3 Melanocyte $\quad 18$ NK Dermal non-immune 19 ILC2 4 Schwann1 21 Th 5 Schwann2 22 Treg 6 Fb1 23 Mast cell 7 Fb2 8 Fb3 9 Pericyte1 10 Pericyte2 $11 \bigcirc$ VE1
12 VE2 13 VVE3 14 LE 1 14 LLE1 24 Plasma cell APCs 25 Mac1 26 Mac2 27 Int. Mac 28 DC1 29 DC2 31 Mono ma (1) 32 Mig. DC 33 M. LC
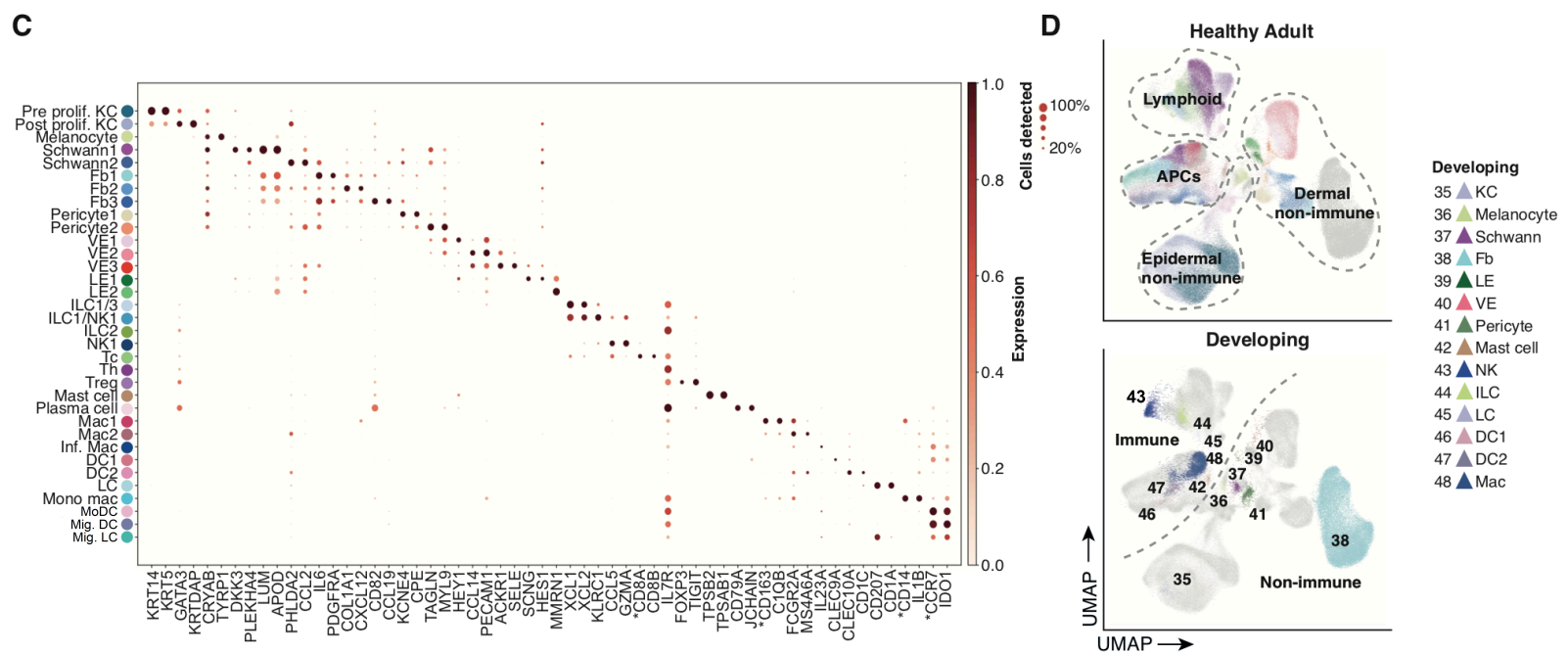

E

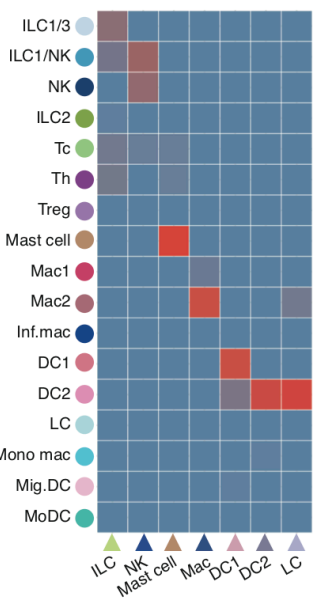

F

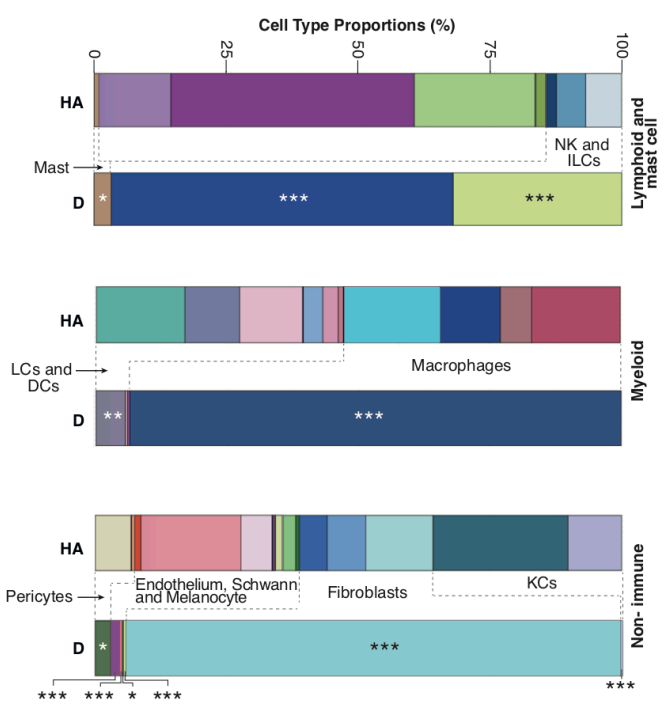




\section{Figure 1. Deconstructing human skin}

(a) Number of cells from scRNA-seq and mass cytometry for each condition and schematic of sampling locations. $\mathrm{AD}=$ atopic dermatitis (b) UMAP visualization showing all cell states found in the healthy adult scRNA-seq data set, $\mathrm{n}=5$. Prolif. $=$ proliferative, $\mathrm{KC}=$ keratinocyte, $\mathrm{Fb}=$ fibroblast, $\mathrm{VE}=$ vascular endothelium, $\mathrm{LE}=$ lymphatic endothelium, ILC = innate lymphoid cell, $\mathrm{NK}=$ natural killer cell, $\mathrm{Tc}=$ cytotoxic $\mathrm{T}$ cell, $\mathrm{Th}=\mathrm{T}$ helper cell, $\mathrm{Treg}=$ regulatory $\mathrm{T}$ cell, Mac $=$ macrophage Inf. = inflammatory, $\mathrm{DC}=$ dendritic cell, $\mathrm{LC}=$ Langerhans cell, Mono mac $=$ monocyte derived macrophage, Mig. = migratory, $\mathrm{MoDC}=$ monocyte derived dendritic cell (c) Dot plot showing the expression of discriminatory markers for each cell state in (b). (d) UMAPs showing the healthy adult cell states found (top) overlaid on the developing cell states $(n=7)$ and the developing cell states (bottom) overlaid on the healthy adult cell states. Cells underlaid are shown in grey. (e) Probability of the cell states found in adult compared to those found in the developing skin using TransferAnchors function in Seurat. (f) Bar charts showing the proportions of each cell states found in adult and developing skin, colors correspond with the legends in (b) and (d). Negative binomial regression comparing developing with adult healthy skin. Statistically significant changes to cell proportion include myeloid cells: DC2, LC and macrophage $(p<0.001)$, lymphoid: ILC and NK $(p<0.001)$, mast cell $(p<0.02)$, fibroblasts, keratinocytes, melanocytes, Schwann cells, VE $(p<0.001)$, LE and pericyte $(p<0.05)$. 


\section{Figure 2. Stromal and endothelial cells}
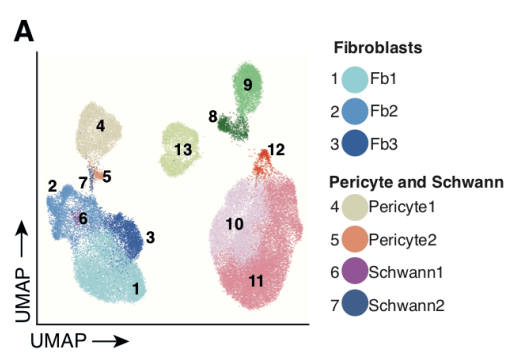

C
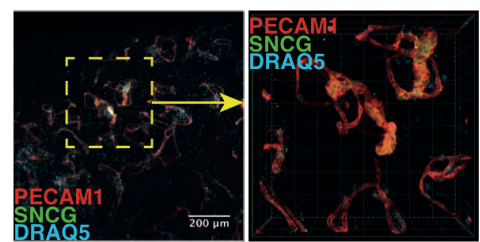

E
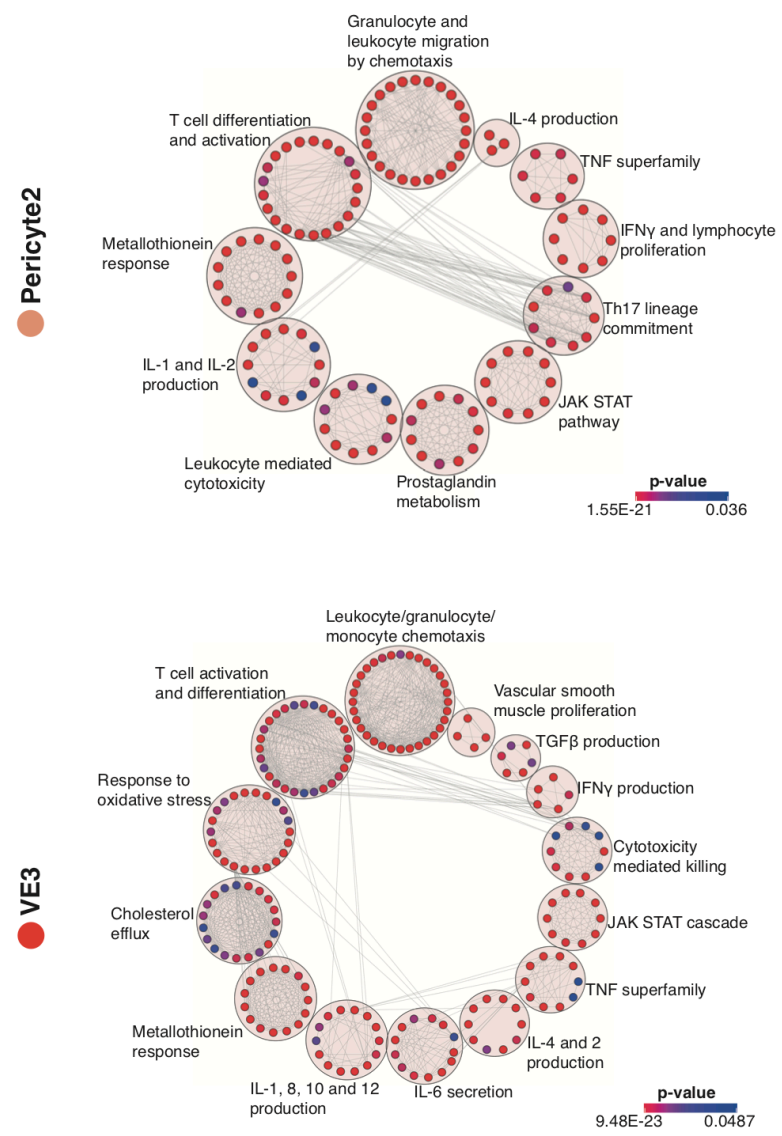

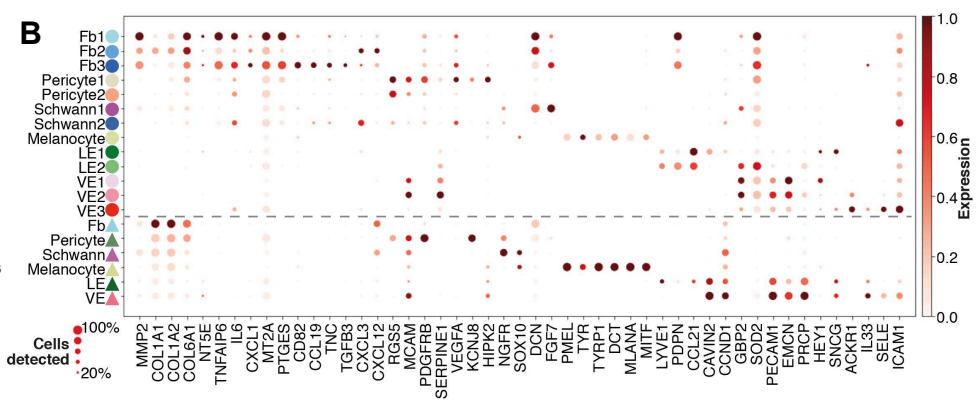

D
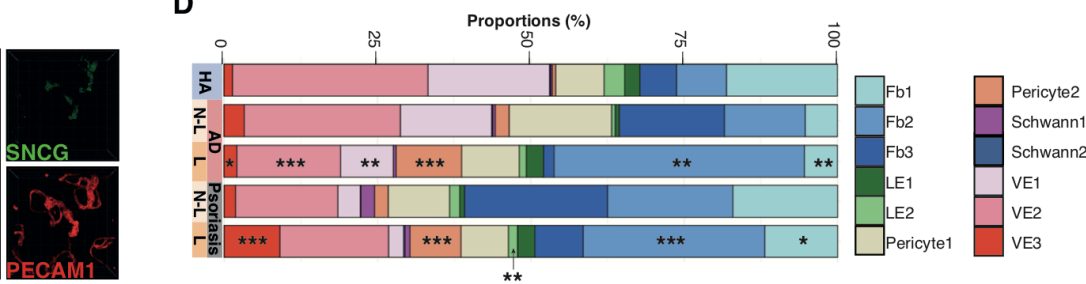

Psoriasis
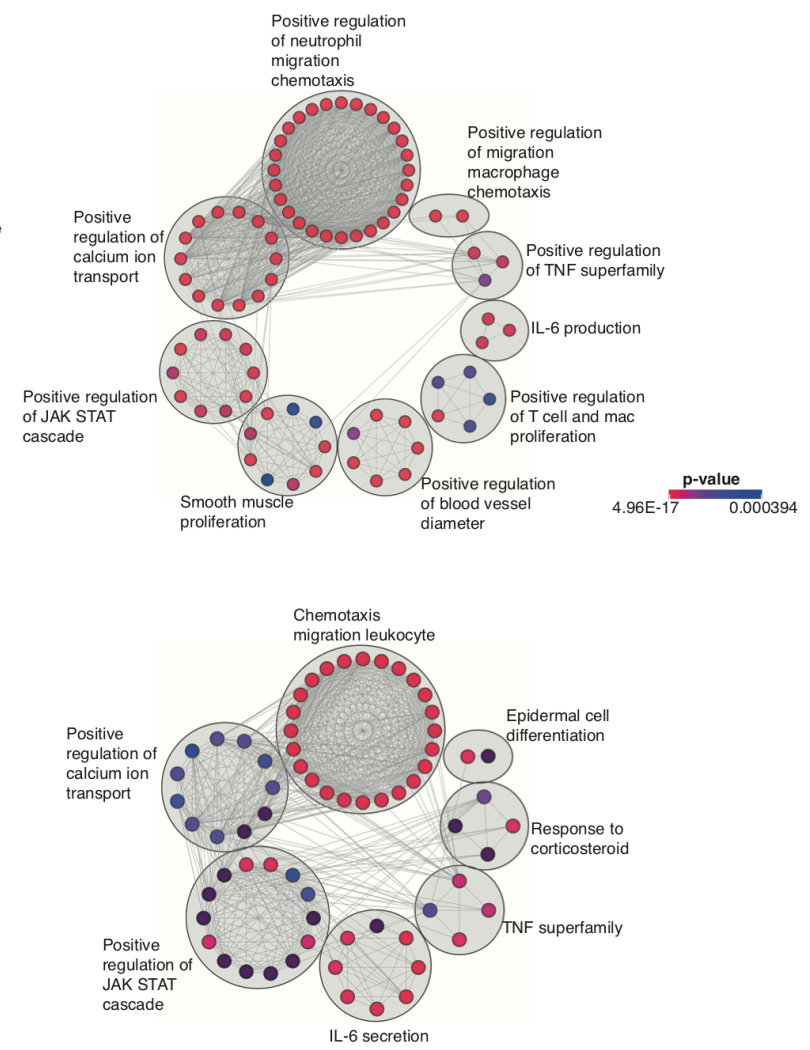

p-value
$2.04 R-18 \quad 0.0045$ 


\section{Figure 2. Stromal and endothelial cells}

(a) UMAP visualization of the non-immune, non-keratinocyte cell states found in the healthy adult skin, $\mathrm{n}=5 . \mathrm{Fb}=$ fibroblast, $\mathrm{LE}=$ lymphatic endothelium, $\mathrm{VE}=$ vascular endothelium. (b) Dot plot showing the expression of differentially expressed genes between the cell states found in (a) and their developmental counterparts, separated by the dotted line. (c) 3D Reconstruction of Z-stacked images of whole mount immunofluorescence staining of dermis for CD31 (PECAM1, red), gamma synuclein (SNCG, green) and DRAQ5 (blue). White cubes represent 40x40x40 $\mu \mathrm{m}$. (d) Bar charts showing the proportions of each cell states found in (a) compared to diseased skin. Negative binomial regression comparing $\mathrm{AD}$ and psoriasis with healthy skin. In $\mathrm{AD}, \mathrm{F} 1(p=<0.05), \mathrm{F} 2(p$ $=<0.001)$, LE2 $(p=<0.01)$, Pericyte2 $(p=<0.001)$, Schwann1 $(p=<0.05)$, VE1 $(p=<0.001)$, VE2 $(p=<0.01)$ and VE3 $(p=<0.001)$ all significantly change compared to healthy. In psoriasis; F1 $(p=<0.01)$, F2 $(p=<0.01)$, Pericyte2 $(p=<0.001)$, VE1 $(p=<0.01)$, VE2 $(p=<0.001)$ and VE3 $(p=<0.05)$, all significant change compared to healthy. HA = healthy adult, $\mathrm{AD}=$ atopic dermatitis, $\mathrm{P}=$ psoriasis. (e) Clustered network visualizations of pathways differentially enriched in VE3 and Pericyte 2 clusters in AD and psoriasis compared to analogous cell clusters in healthy skin. Network nodes are colored by enrichment score $(p=<0.05)$ and represent individual enriched gene sets whilst edges represent shared genes between nodes (intersect $>=10 \%$ ). 


\section{Figure 3. Keratinocyte cell states in health, AD and psoriasis}

A

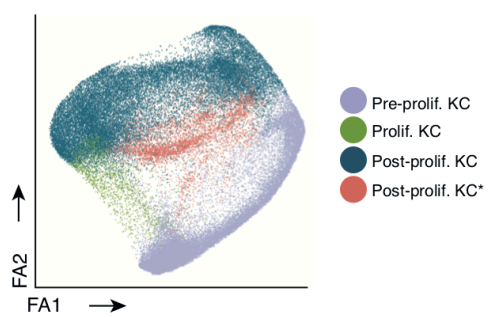

D
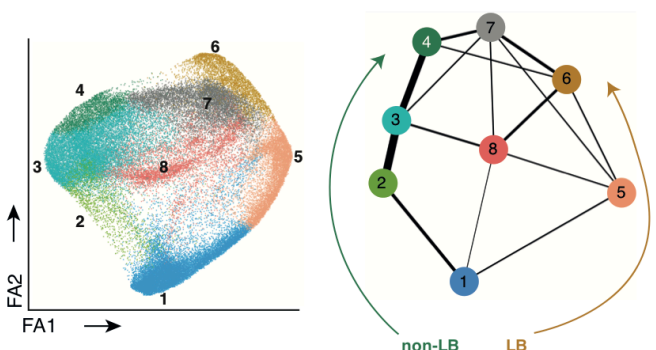

$\mathbf{E}$

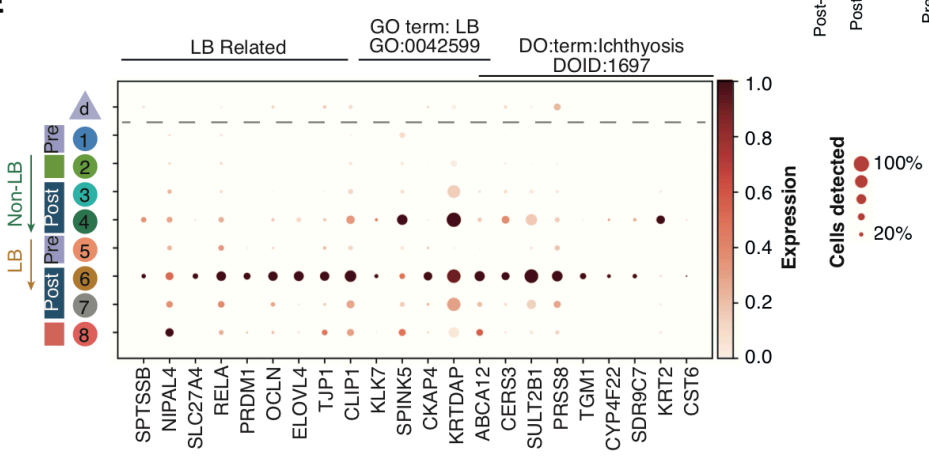

G

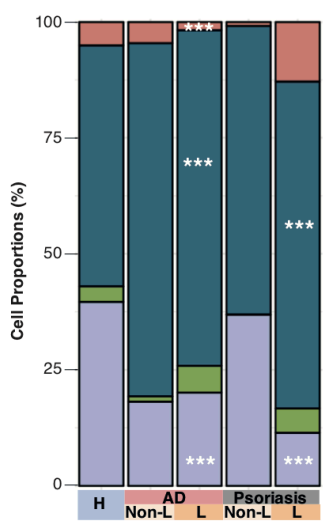

B

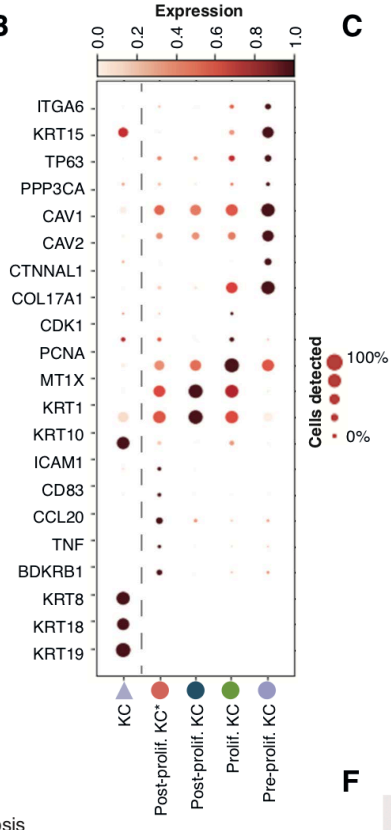

$\mathbf{F}$

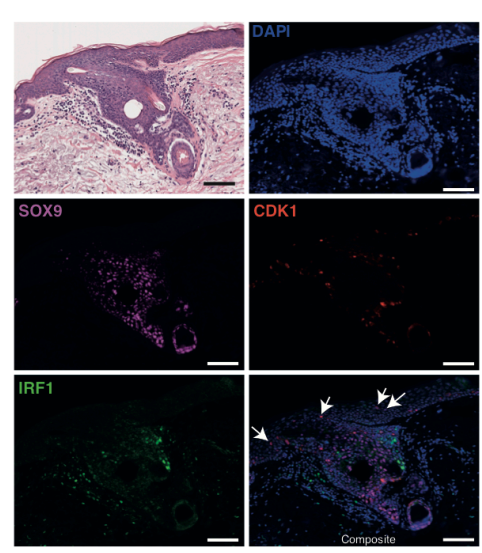

Psoriasis

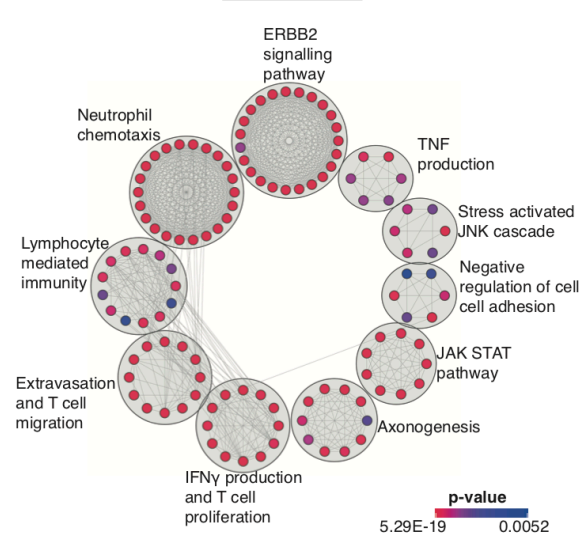




\section{Figure 3. Keratinocyte cell states in health, AD and psoriasis}

(a) Force-directed graph (FDG) visualization of the different keratinocyte cell states found in healthy adult skin. Prolif = proliferating, $\mathrm{KC}=$ keratinocyte. Asterix indicates the cell state with inflammatory markers, $n=5$. (b) FDG feature plots showing gene expression of markers of the cell states found in (a), together with images of these markers in situ, from the Human Protein Atlas. Scale bars represent $100 \mu \mathrm{m}$. (c) Dot plot showing the expression of differentially expressed genes between the cell states found in (a) and their developmental counterparts, separated by the dotted line. (d) Left panel: FDG in (a) annotated by Leiden clustering of eight groups; preproliferation (clusters 1, 5), dividing (cluster 2), post-proliferation differentiating (clusters 3, 4, 6, 7, 8). Right panel: PAGA showing the relative connectivity between the keratinocyte clusters. Arrows indicate the two differentiation pathways of basal keratinocytes to suprabasal: LB = lamellar body. (e) Dot plot of genes related to lamellar body production and ichthyosis on the clusters presented in (d), as well as fetal keratinocytes. (f) Immunofluorescence staining of healthy adult skin for DAPI (blue), SOX9 (purple), CDK1 (red), IRF1 (green). Top left image shows an $\mathrm{H} \& \mathrm{E}$ stained sequential section. White arrows indicate $\mathrm{CDK} 1^{+}$cells in suprabasal layers Images representative of $\mathrm{n}=3$. Scale bars represent $100 \mu \mathrm{m}$. (g) Bar charts showing the proportions of the keratinocyte cell states in healthy and diseased skin. The proportions of post prolif. KC, post prolif. $\mathrm{KC}^{*}$ and pre prolif. $\mathrm{KC}$ are all significantly different in lesional AD compared to healthy ( $p$-values $<0.001)$. The proportions of post prolif. $\mathrm{KC}$ and pre prolif. $\mathrm{KC}$ are both significantly different in lesional psoriasis compared to healthy ( $p$-values $<0.001$ ). (h) Clustered network visualizations of pathways differentially enriched in post prolif $\mathrm{KC}$ clusters in $\mathrm{AD}$ and psoriasis compared to analogous cell clusters in healthy skin. Network nodes are colored by enrichment score $(p=<0.05)$ and represent individual enriched gene sets whilst edges represent shared genes between nodes (intersect $>=10 \%$ ). 
Figure 4. Skin innate lymphoid cells, T lymphocytes and TCR analysis

A

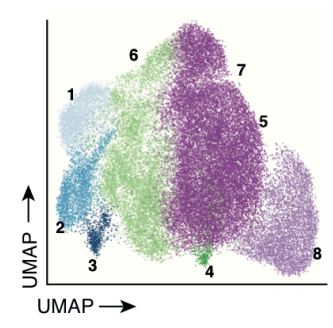

C

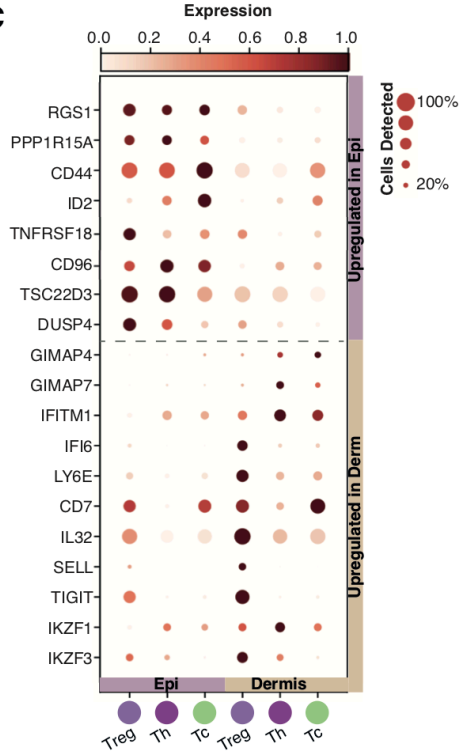

B

$1 \mathrm{ILC}_{1 / 3}$

$2 \mathrm{LLC1/NK}$ $3 \mathrm{NK}$

${ }_{4}$ ILC2

5 Plasma

6 TC

$7 \mathrm{Th}^{\mathrm{T}}$

8 Treg

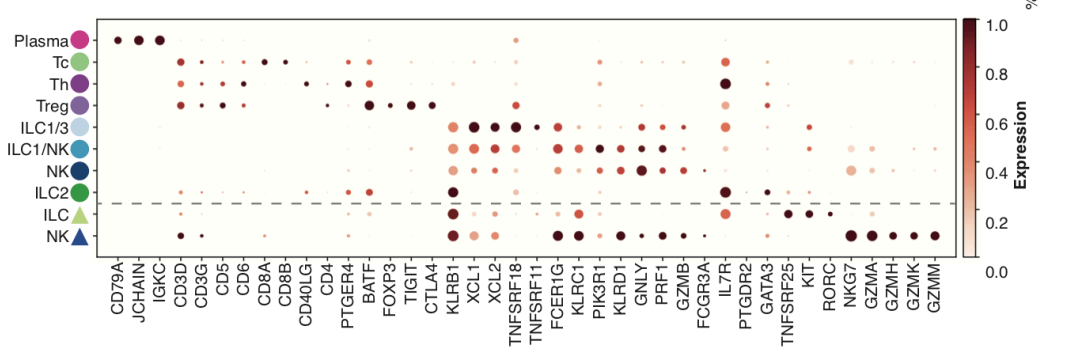

D

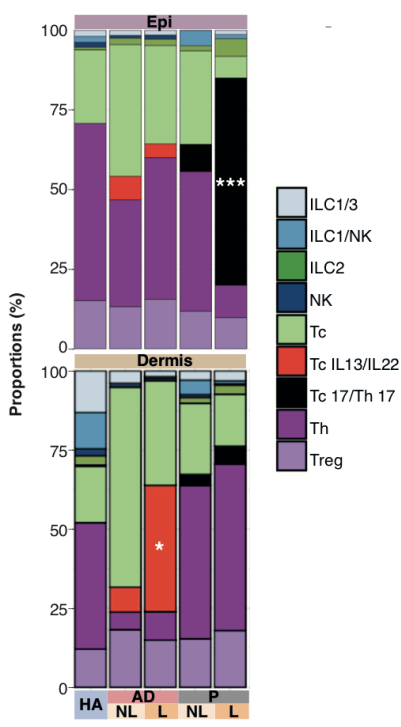

E

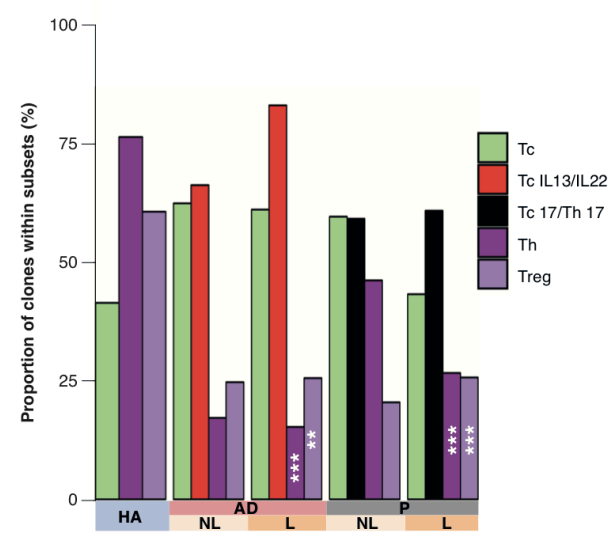




\section{Figure 4. Skin innate lymphoid cells, T lymphocytes and TCR analysis}

(a) UMAP visualization of the different lymphoid and mast cell states found in healthy adult skin. ILC = innate lymphoid cell, $\mathrm{NK}=$ natural killer cell, $\mathrm{Tc}=$ cytotoxic $\mathrm{T}$ cell, $\mathrm{Th}=\mathrm{T}$ helper cell, Treg $=$ regulatory $\mathrm{T}$ cell, $\mathrm{n}=5$ (b) Dot plot showing the expression of differentially expressed genes between the cell states found in (a) and their developmental counterparts, separated by the dotted line. (c) Dot plot showing the differentially expressed genes in the $\mathrm{T}$ cell subsets between epidermis and dermis in healthy adult skin, Epi = epidermis, Derm= dermis. (d) Bar charts showing the proportions of the lymphoid cell states in healthy and diseased skin. Lesional dermal AD skin is enriched for TcIL13/IL22 compared to non lesional ( $p$-value $=0.04)$, and psoriasis lesional skin is enriched for Tc17/Th17 in the epidermis ( $p$-value $<0.001)$. Significance of other cell states were not tested. $\mathrm{HA}=$ healthy adult, $\mathrm{AD}=$ atopic dermatitis, $\mathrm{P}=$ psoriasis, $\mathrm{L}=$ lesional, $\mathrm{NL}=$ non lesional. (e) Bar charts showing the proportion of cells from expanded clonotypes for each T cell subset in health and disease. Proportions are significantly lower for Th (AD $p$-value $<0.001$, Psoriasis $<0.001)$ and Treg (AD $p$-value $<0.01$, Psoriasis $<0.001)$ in lesional disease compared to healthy. 


\section{Figure 5. Dermal and epidermal mononuclear phagocytes}

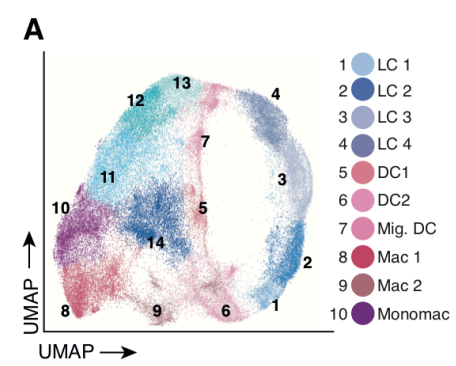

C

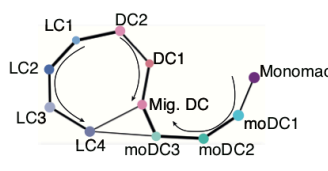

Murine Splenic DC1

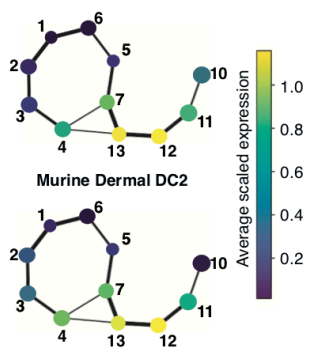

G

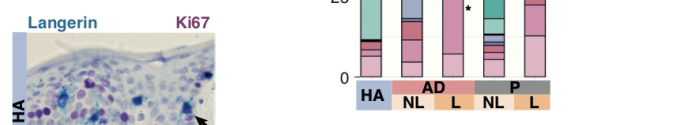

B

$13 \mathrm{MoDC} 3$

14 Inf. Mac

D

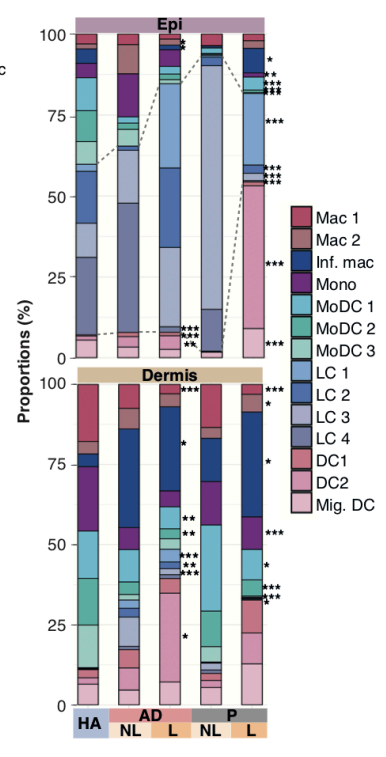

E

H
$11 \bigcirc \mathrm{MoDC} 1$
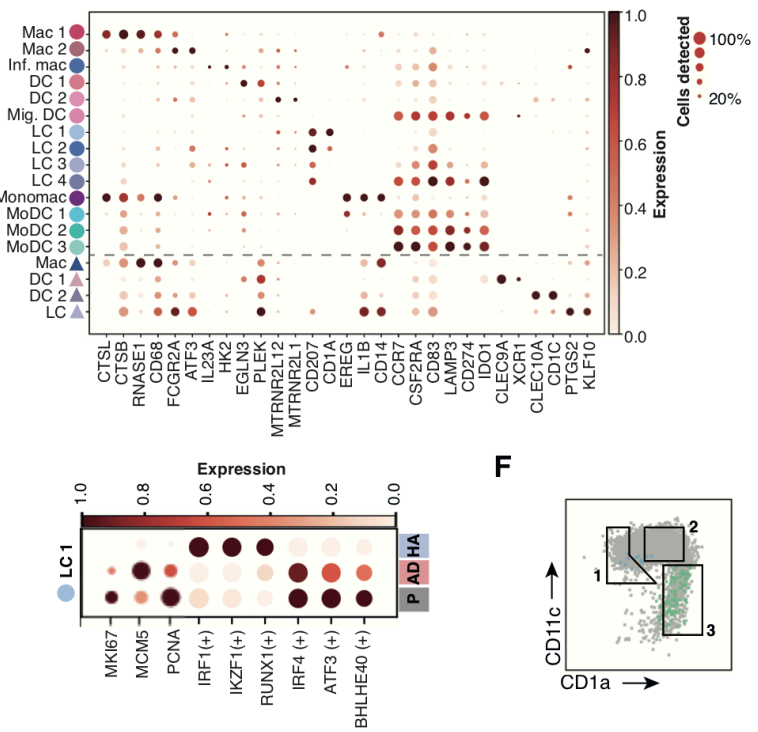

F
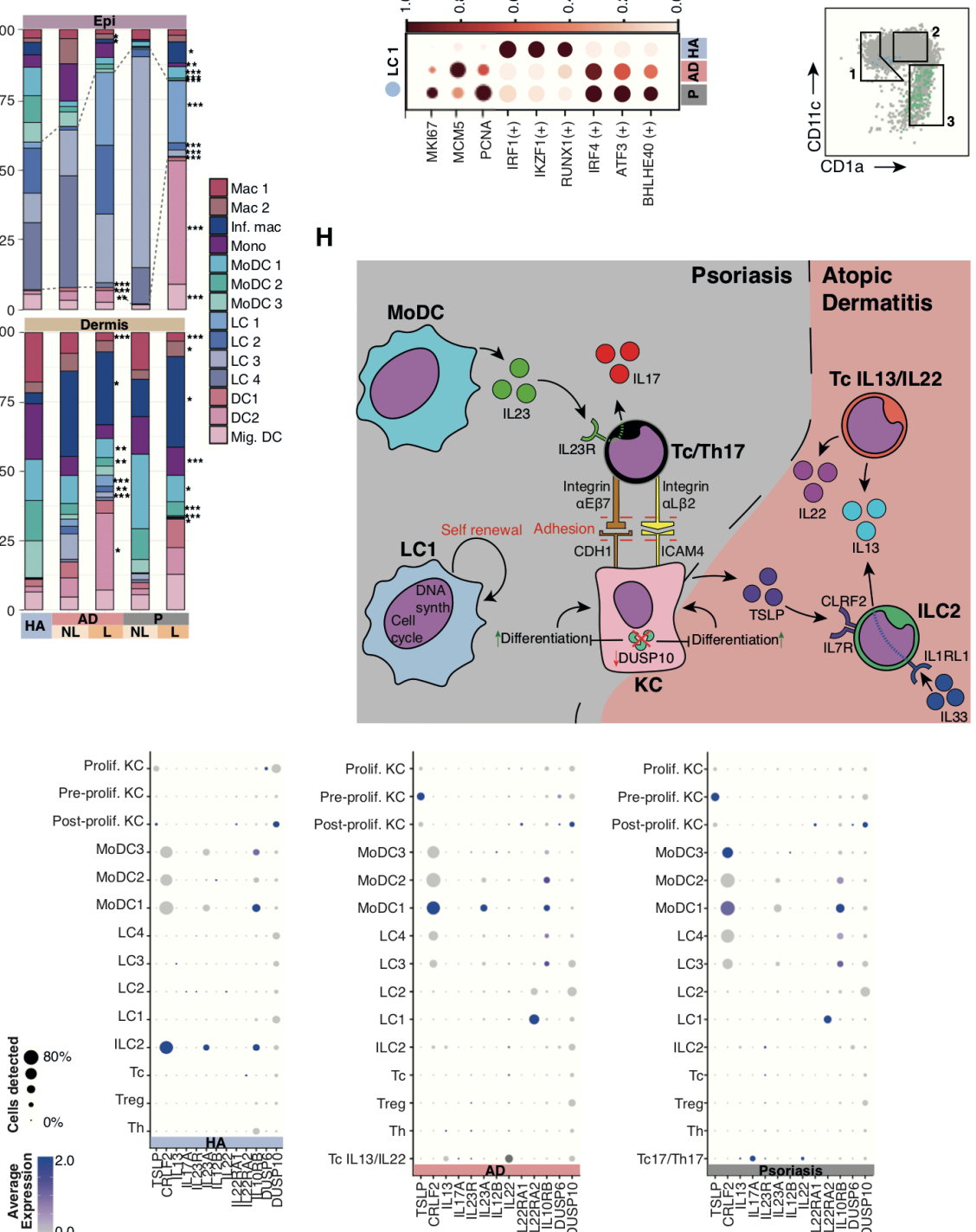

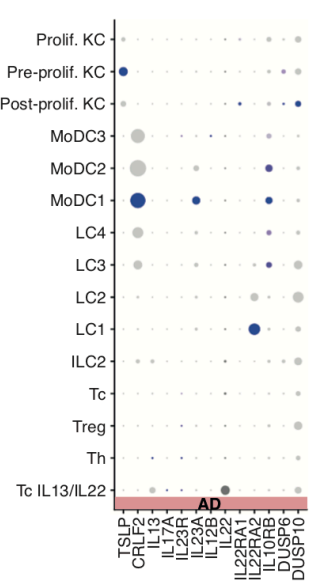




\section{Figure 5. Dermal and epidermal mononuclear phagocytes}

(a) UMAP visualization of different antigen presenting cell (APC) states found in adult healthy $(\mathrm{n}=5), \operatorname{AD}(\mathrm{n}=4)$ and psoriasis $(\mathrm{n}=3) . \mathrm{LC}=$ Langerhans cell, $\mathrm{DC}=$ dendritic cell, Mig. = migratory, $\mathrm{Mac}=$ macrophage, Mono $=$ monocyte derived macrophage, $\mathrm{MoDC}=$ monocyte derived dendritic cell, inf. = inflammatory. (b) Dot plot showing the expression of differentially expressed genes between the cell states found (a) and their developmental counterparts, separated by the dotted line. (c) Upper panel: abstracted graph (PAGA) showing connectivity between previously defined clusters. The size of the nodes is proportional to cluster size and edge thickness is proportional to the strength of the connection between nodes. Lower panel: enrichment of gene signatures for murine splenic Xcr1 ${ }^{+} \mathrm{DC}$ (DC1) and dermal CD11c ${ }^{+}$(DC2) in each node. (d) Bar charts showing the proportions of MP cell states in healthy, AD and psoriasis skin. In the epidermis proportions of the following cell types significantly change in AD: Mac2 ( $p$-value $<0.05)$, Inf. mac ( $p$-value $<0.05)$, LC4 ( $p$-value $<0.001)$, DC1 ( $p$-value $<0.001)$, DC2 ( $p$-value $<0.01)$. In the epidermis proportions of the following cell types significantly change in psoriasis: Inf.mac ( $p$-value $<0.05)$, mono mac ( $p$-value $<0.01)$, moDC1 $(p$-value $<0.001)$, moDC2 ( $p$-value $<0.001)$, moDC3 ( $p$-value $<0.001)$, LC2 ( $p$-value $<0.001)$, LC3 ( $p$-value $<0.001)$, LC4 ( $p$-value $<0.001)$, DC2 ( $p$-value $<0.001)$ and mig. DC ( $p$-value <0.001). In the dermis proportions of the following cell types significantly change in AD: Mac1 ( $p$-value $<0.001)$, Inf. mac ( $p$-value $<0.05)$, moDC1 ( $p$-value $<0.01)$, moDC2 ( $p$-value $<0.01)$, LC1 ( $p$-value $<0.001)$, LC2 ( $p$-value $<0.01)$, LC3 ( $p$-value $<0.001)$ and DC2 ( $p$-value <0.01). In the dermis proportions of the following cell types significantly change in psoriasis: Mac1 ( $p$-value $<0.001)$, Mac2 ( $p$-value $<0.01)$, Inf. Mac ( $p$-value $<0.01)$, monomac ( $p$-value $<0.001)$, moDC1 ( $p$-value $<0.01)$, moDC2 ( $p$-value $<0.001), \operatorname{moDC} 2$ ( $p$-value $<0.001)$ and LC1 ( $p$-value $<0.01)$. (e) Dot plot showing expression of genes associated with proliferation and transcription factors predicted to control the different gene profiles in healthy and diseased skin. (f) Overlay plot of index-sorted epidermal LC1 (light blue) and moDC (green) on all epidermal APCs (live, single, CD45 ${ }^{+} \mathrm{HLA}_{-} \mathrm{DR}^{+} \mathrm{CD} 3^{-}$) (grey) (g) Dual stained sections of healthy epidermis stained for Langerin (blue) and Ki67 (purple). Bar chart showing the percentage of Langerin ${ }^{+}$cells expressing Ki67 in the epidermis of adult healthy skin ( $\left.n=3\right)$, AD $(n=4)$ and psoriasis $(n=3)$. (h) Illustration of predicted cell network interactions active in atopic 
bioRxiv preprint doi: https://doi.org/10.1101/2020.11.05.369363; this version posted November 5, 2020. The copyright holder for this preprint (which was not certified by peer review) is the author/funder. All rights reserved. No reuse allowed without permission.

dermatitis and psoriasis epidermis respectively. (i) Dot plots showing expression of genes forming part of the predicted cellular network in AD and psoriasis (based on (h)). 


\section{Materials and Methods}

RF-10 media consists of Roswell Park Memorial Institute media (RPMI)(Sigma, R0883) supplemented with 10\% fetal calf serum (FCS) (Life technologies, 10270106), 100U/ml Penicillin (Sigma, P0781), $100 \mu \mathrm{g} / \mathrm{ml}$ Streptomycin (Sigma, P0781) and 1\% (v/v) LGlutamine (Sigma, G7513). Flow buffer consists of Dulbecco's phosphate buffered saline (PBS)(Sigma, D8537) supplemented with 2\% (v/v) FCS and 2mM EDTA (Sigma, E7889). Wash buffer consists of PBS supplemented with 2\% FCS.

\section{Ethics statement}

Patients who donated adult healthy skin and biopsies of atopic dermatitis and psoriasis gave written informed consent, in accordance with the Newcastle and North Tyneside 1 Research Ethics Committee (Newcastle Dermatology Biobank - REC reference: 08/H0906/95+5). Adult healthy skin was donated from normally discarded surplus skin from mammoplasty surgery. Patients with atopic dermatitis and psoriasis consented to a $6 \mathrm{~mm}$ punch biopsy from lesional and non-lesional skin (at least $2 \mathrm{~cm}$ away from lesion) (Table S2). All patients were naive to biologics treatment, had been free of any other systemic treatment for at least 4 weeks and free of topical corticosteroids for 1 week. Human embryonic and fetal skin was obtained from the MRC/Wellcome Trust-funded Human Developmental Biology Resource (HDBR; http://www.hdbr.org/)(94) with appropriate written consent and approval from the Newcastle and North Tyneside NHS Health Authority Joint Ethics Committee $(08 / \mathrm{H} 0906 / 21+5)$. HDBR is regulated by the UK Human Tissue Authority (HTA; www.hta.gov.uk) and operates in accordance with the relevant HTA Codes of Practice.

\section{Fetal developmental stage assignment and chromosomal assessment}

Embryos up to 8 post conception weeks (PCW) were staged using the Carnegie staging method (95). After $8 \mathrm{PCW}$, developmental age was estimated from measurements of foot length and heel to knee length and compared against a standard growth chart (96). A piece of skin, or where this was not possible, chorionic villi tissue was collected from every sample for Quantitative Fluorescence-Polymerase Chain Reaction analysis using markers for the sex chromosomes and the following autosomes 13, 15, 16, 18, 21, 22, 
which are the most commonly seen chromosomal abnormalities. All samples were karyotypically normal.

\section{Generation of single cell suspension from adult skin}

Healthy skin was cut to thin strips in PBS and the top $200 \mu \mathrm{m}$ layer was taken using a dermatome with a Pilling Wecprep blade and a .008 gauge Goulian guard. A grid of slits was cut into the skin sheets to aid enzymatic access and the skin was then treated with 2U/ml dispase II (Roche, 04942078001) in RPMI at $37^{\circ} \mathrm{C}$ for 1 hour. The epidermis was peeled from the dermis, and both fragments were separately digested in a petri-dish at $37^{\circ} \mathrm{C} 5 \% \mathrm{CO} 2$ in RF-10 media with $1.6 \mathrm{mg} / \mathrm{ml}$ type IV collagenase (Worthington, CLS4) overnight (12 hours). All work was done within class II biological safety cabinets using autoclave-sterilized equipment. The media was then collected with a serological pipette and filtered through a sterile $100 \mu \mathrm{m}$ cell strainer (BD Falcon, 352360). The petri dish and strainer were washed through with RF-10 to collect any remaining cells. Cells were pelleted by centrifuging at $500 \mathrm{x} g$ for 5 minutes. Supernatant was discarded and the pellet resuspended in $1 \mathrm{ml}$ RF-10 by gently pipetting up and down. Cells were then counted by taking off $10 \mu \mathrm{l}$, mixing 1:1 with $0.4 \%$ trypan blue (Sigma, T8154) to stain dead cells and counting on a hemocytometer. The $6 \mathrm{~mm}$ punch biopsies from AD and psoriasis patients' skin were trimmed of the lower dermis and subcutis, and cut in half using a scalpel. The biopsies were then treated with $2 \mu \mathrm{l}$ of dispase II in RPMI at $37^{\circ} \mathrm{C}$ for 2 hours. The epidermis was peeled from the dermis, and the remaining tissue processing was the same as written above for healthy skin.

\section{Flow cytometry analysis of cell suspensions}

Suspensions of dermal or epidermal cells were resuspended in $100 \mu$ of flow buffer per $10^{7}$ cells, transferred to polystyrene FACS tubes (BD Falcon, 352054) and stained with 5 $\mu l$ of each antibody (Table S3) per $10^{7}$ cells for 30 minutes at $4^{\circ} \mathrm{C}$ in the dark. Cells were washed by diluting in flow buffer and centrifuging at $500 \mathrm{x} \mathrm{g}$ for 5 minutes, then resuspended in $200 \mu \mathrm{l}$ of flow buffer per $10^{6}$ cells with $3 \mu \mathrm{M}$ DAPI (Sysmex Partec, 055005). Cells were then run through a Fortessa X20 for analysis. Flow cytometry analysis 
was performed with FlowJo V10 (FlowJo LLC, USA), and the plots were prepared with GraphPad Prism 7.00 (GraphPad Software, La Jolla California USA).

\section{Single cell sorting of skin cells}

Suspensions of dermal or epidermal cells were resuspended in $100 \mu$ of flow buffer per $10^{7}$ cells, transferred to polypropylene FACS tubes (BD Falcon, 352063) and stained with $5 \mu \mathrm{l}$ of each antibody per $10^{7}$ cells for 30 minutes at $4^{\circ} \mathrm{C}$ in the dark. Cells were washed by diluting in flow buffer and centrifuging at $500 \mathrm{x} g$ for 5 minutes, then resuspended in 1 $\mathrm{ml}$ of sort buffer per $20 \times 10^{6}$ cells with $3 \mu \mathrm{M}$ DAPI. Cells were then filtered using a 100 $\mu \mathrm{m}$ cell strainer and sorted using a FACSFusion Sorter with a $100 \mu \mathrm{m}$ fluidics nozzle.

\section{Mass cytometry analysis of cell suspensions}

Suspensions of dermal or epidermal cells were incubated with $2.5 \mu \mathrm{M}$ Cell-ID Cisplatin (Fluidigm, 201064) for $5 \mathrm{~min}$ at RT before washing twice in wash buffer at $500 \mathrm{x} \mathrm{g}$ for 5 minutes. Cell-surface antigens were labelled with a master mix of metal-tagged antibodies (Table S3) for 1 hour at room temperature in wash buffer. After washing twice in PBS (500 x g, 5 minutes), cells were fixed for 30 minutes at RT in a solution of 0.5x Fix Buffer (OXP3 buffer set, eBiosciences, 00-5523-00) supplemented with 1.6\% formaldehyde (Polysciences, 18814). Post-fixation, the cells were washed twice in permeabilization buffer (FOXP3 buffer set, eBiosciences, 00-5523-00) and subsequently incubated with an intracellularly targeted antibody cocktail for 1 hour at RT. Unbound antibody was removed by washing twice in PBS prior to incubating the cells in Iridium intercalator (Fluidigm, 201192A) at $125 \mathrm{nM}$ in PBS for 1 hour. A final fix was performed in $1.6 \%$ formaldehyde for 30 minutes at RT, washed twice in PBS and twice in $\mathrm{dH} 2 \mathrm{O}$. Cell pellets were finally resuspended at $0.5 \times 10^{-6}$ cells $/ \mathrm{mL}$ in $\mathrm{dH} 2 \mathrm{O}$ with $10 \%(\mathrm{v} / \mathrm{v}) \mathrm{EQ}$ beads (Fluidigm, 201078) for analysis on the Helios mass cytometer (Fluidigm).

\section{Single cell RNA-seq}

For the droplet-encapsulation scRNA-seq experiments, 7000 live, single cells were loaded onto each channel of the Chromium chip (10x Genomics, Pleasanton, CA, USA) before droplet encapsulation on the Chromium Controller. Sequencing libraries were 
generated using the Single Cell 3' or 5' plus TCR enrichment reagent kits as per the manufacturer's protocol. Libraries were sequenced using an Illumina HiSeq 4000 using v4 SBS chemistry to achieve a minimum depth of 50,000 raw reads per cell using the following parameters: Read1: 26 cycles, i7: 8 cycles, i5: 0 cycles; Read2: 98 cycles.

For the plate-based scRNA-seq experiments, a slightly modified Smart-seq2 protocol was used as previously described (68). After cDNA amplification, libraries were prepared (384 cells per library) using the Illumina Nextera XT kit (Illumina Inc, San Diego, CA, USA). Index v2 sets A, B C and D were used per library to barcode each cell before multiplexing. Each library was sequenced to achieve a minimum depth of 1-2 million raw reads per cell using an Illumina HiSeq 4000 using v4 SBS chemistry to generate $75 \mathrm{bp}$ paired end reads.

\section{Whole mount immunofluorescence staining of dermis and epidermis}

Peeled dermis and epidermis sheets were cut to $1 \mathrm{~cm}^{2}$ and fixed in $2 \%$ formaldehyde (Polysciences, 18814) and 30\% sucrose in PBS for 24 hours at $4^{\circ} \mathrm{C}$. Dermis and epidermis sheets were incubated in $300 \mathrm{mM}$ glycine for 24 hours at $4^{\circ} \mathrm{C}$, washed in PBS then blocked and permeabilized in PBS with 20\% goat serum (R\&D Systems, DY005) and $0.2 \%$ Triton X-100 (Sigma, T8787) for 24 hours at $4^{\circ} \mathrm{C}$ then washed in PBS with $0.1 \%$ Triton X-100. Primary antibodies were added in PBS with $20 \%$ goat serum and $0.1 \%$ Triton X-100 for 48 hours then washed. Secondary antibodies were added in PBS with $20 \%$ goat serum and $0.1 \%$ Triton X-100 for 24 hours then washed. Spectral DAPI (Perkin Elmer, FP1490) or DRAQ5 (Abcam, ab108410) was added as per manufacturer's instructions. Sheets were mounted in Vectashield antifade mounting medium (Vector Laboratories, H-1000) and set for at least 24 hours before imaging. Slides were imaged using a Zeiss LSM800 Airyscan/Spinning disk Confocal Microscope and Zeiss Pro software (Zeiss, Germany). Z stack images were reconstructed using Zeiss Pro software.

\section{Immunohistochemistry}

Formalin fixed paraffin embedded blocks of mammoplasty skin were sectioned at $4 \mu \mathrm{m}$ thickness onto APES-coated slides. Sections were dewaxed for 5 minutes in Xylene 
(Fisher Chemical) then rehydrated through graded ethanol (99\%, 95\% and 70\%; Fisher Chemical) and washed in running water. Sections were treated with hydrogen peroxide block ( $1 \% \mathrm{v} / \mathrm{v}$ in water; Sigma) for 10 minutes and rinsed in tap water prior to antigen retrieval, using citrate buffer, $\mathrm{pH} 6$ and pressure heating. Slides were washed with TBS, pH 7.6 for 5 minutes prior to staining. Staining was done using the Vector Immpress Kit (Vector Laboratories). Sections were blot dried and blocked sequentially with $2.5 \%$ normal horse serum, avidin (Vector Laboratories) and then biotin (Vector Laboratories) for 10 minutes each and blot dried in between. Sections were incubated for 60 minutes with primary antibody (Table S3) diluted in TBS pH 7.6 and washed twice in TBS pH 7.6 for 5 minutes each before incubation for 30 minutes with the secondary antibody supplied with the kit. Slides were washed twice in TBS pH 7.6 for 5 minutes each, and developed using peroxidase chromogen $\mathrm{DAB}$, or an AP substrate for multi-colored staining. Sections were counterstained in Mayer's Haematoxylin for 30 seconds, washed and put in Scots tap water for 30 seconds. Slides were dehydrated through graded ethanol (70\% to $99 \%$ ) and then placed in Xylene prior to mounting with DPX (Sigma-Aldrich). Sections were imaged on a Nikon Eclipse 80i microscope using NIS-Elements Fv4 or Zeiss LSM800 Airyscan/Spinning disk Confocal Microscope and Zeiss Pro software (Zeiss, Germany). The Human Protein Atlas (version 18.1)(www.proteinatlas.org)(97) was used for Figure 3. For a list of URLs pointing to the original photos, see Table S4. The Gene Ontology (The Gene Ontology Consortium, 2019)(http://geneontology.org, version: 2019/03/01), the Disease Ontology (98) (http://disease-ontology.org, release date: 2019-05-20T12:00:30.342164Z) and the MGD 6.13 (99) databases were used to find ichthyosis-related genes.

\section{Immunohistochemistry Scoring}

Dual stained IHC for Ki67 and Langerin were manually counted using a Nikon Eclipse $80 \mathrm{i}$ microscope. The number of Langerin ${ }^{+}$and $\mathrm{Ki} 67^{+}$Langerin $^{+}$cells were counted in a $3 \mathrm{~mm}$ section of epidermis for healthy skin, $\mathrm{AD}$ and psoriasis. The percentage of dual stained $\mathrm{Ki}^{+} 7^{+}$Langerin $^{+}$cells out of total Langerin ${ }^{+}$cells was calculated. 


\section{Data analysis}

Alignment, quantification and quality control of scRNA-seq data

Droplet-based (10x) sequencing data was quantified using the Cell Ranger Single-Cell Software Suite (version 3.1.0, 10x Genomics Inc) and aligned to the GRCh38 reference genome (official Cell Ranger reference, version 3.0.0). Smart-seq2 sequencing data was aligned with STAR (version 2.5.1b), using the STAR index and aligned to the same GRCh38 reference genome. Gene-specific read counts were calculated using htseq-count (version 0.10.0). Cells with fewer than 200 detected genes and for which the total mitochondrial gene expression exceeded $20 \%$ were removed. Genes that were expressed in fewer than 3 cells were also removed.

Doublet detection and exclusion, data normalization, scaling and feature selection

We applied Scrublet (v0.2.1), using an exclusion threshold of median plus four times median absolute deviation of the doublet scores (100). Data normalization was performed using the normalize_per_cell function in scanpy (v1.4.3, and throughout unless stated otherwise) in Python (v3.6.9) to correct for cell-to-cell variation (11). Expression values of each gene were scaled and centered using the scale function in scanpy. Highly variable genes were detected using the highly_variable_genes function in scanpy with minimum cut-off values 0.0125 and 0.5 for expression and dispersion.

\section{Data embedding, visualization and clustering}

Principal components were calculated using scanpy.pca and adjusted for donor-to-donor variation using the bbknn package (v1.3.2)(10) for batch correction. Dimensionality reduction and embedding was performed using Uniform Manifold Approximation and Projection (UMAP) by the scanpy.tl.umap function. The resultant k-nearest neighbors graph was clustered using the Leiden graph-based method (scanpy.tl.leiden)(101).

\section{Cluster annotation}

Differentially expressed genes were calculated using the Wilcoxon sum rank test restricted to genes expressed in at least $30 \%$ of cells in either of the two populations compared, and with a fold change cutoff of 0.25 (natural log scale). All $p$-values were 
adjusted for multiple testing using the Bonferroni correction. Initial annotation was ascribed by comparing these DEGs to published bulk transcription profiles or protein expression of defined cell types. Following this, four major groups (lymphoid cells, myeloid cells, keratinocytes, and other non-immune cells) were subset for further rounds of feature selection, embedding, visualization and clustering using the same pipeline. For a list of top 30 marker genes for each annotated cell type, see Table S1.

\section{Trajectory analysis}

Reconstruction of differentiation pathways of both APCs and keratinocytes was performed using partition-based approximate graph abstraction (PAGA) in Scanpy v1.4 (sc.tl.paga) (Wolf et al., 2019). PAGA represents clusters with nodes, and edge weights (thickness) quantify the connectivity between groups. Connectivity is a measure of the fraction of inter-cluster edges in the full neighborhood graph of single cells. Diffusion pseudotime values were assigned to cells along the resultant differentiation pathways using scanpy (scanpy.tl.dpt). The R (v3.5.2) (R Core Team 2018) Monocle (v2.6.4) DifferentialGeneTest function was used to calculate differentially expressed genes (adjusted $p$-value $<0.001$ ) along each differentiation pathway as a function of their progression through pseudotime (35). Transcription factors were identified using The Human Transcription Factor list (v1.01) (102).

\section{Comparison and correlation between adult and fetal cell types}

Adult and fetal datasets were merged in Seurat and both highly variable genes and principal components (PCs) calculated in the combined dataset. To adjust for both sample and stage-related effects the neighborhood graph was calculated with BBKNN using individual samples as the batch key (10). UMAP embeddings were calculated based on the BBKNN-derived neighborhood graph and visualized as a scatter plot (Fig. 1D). We used the FindTransferAnchors function in Seurat (13) to build a correspondence between the fetal (query) and adult (reference) datasets. The resultant prediction scores for each cell were mean averaged by adult clusters and used to produce a heatmap (Fig. 1E). 


\section{$V(D) J$ data analysis}

Expanded clonotypes for each cell type were defined as having at least two clones, and the proportions express the ratio of expanded cells to cells with V(D)J data annotation. The Shannon index was calculated to compare clonotype diversity between samples. Each sample was randomly down-sampled to the size of the smallest sample 100 times, and the median of the 100 calculated indices was used. The V(D)J data analysis scripts are available as a Python package (v0.1.2; https://github.com/veghp/pyVDJ).

\section{Differences in cell type proportions between conditions}

A negative binomial regression model of the counts of cell types was used for testing for difference in cell type proportions between conditions, as described in Montoro et al., 2018. The negative binomial model was fitted using glm.nb from the MASS R package, and the $p$-value for the significance of the change in proportion between conditions was assessed using a likelihood-ratio test, computed using the anova function.

\section{Gene expression plots}

To compare gene expression in the fetal and adult datasets, raw data were merged using the concatenate function in Scanpy. Mean gene expression by cluster was displayed using the dotplot function in Scanpy. The percentage of cells within a cell type expressing a gene were indicated by dot size, and relative expression level was indicated by color intensity. Only dots with more than $10 \%$ of cells expressing the given gene were drawn.

\section{Comparison between human and mouse DCs}

Gene signatures were generated from publicly available datasets of murine splenic Xcr1 ${ }^{+}$

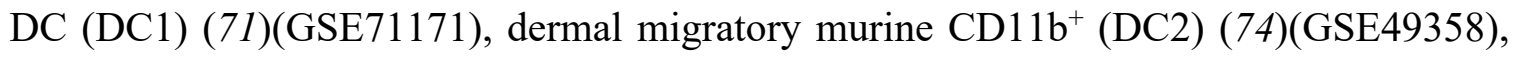
human migratory tonsil and ascites DCs (76)(GSE115006 and GSE115007) as well as our own SmartSeq2 data from 3 rheumatoid arthritis synovial fluid donors. For each a list of DEGs (adjusted $p$-value $<0.05$ ) between the migratory DC cluster and all other MPs was generated to produce a gene signature. Enrichment scores of these signatures in adult skin was calculated using the AddModuleScore function in Seurat. 


\section{Cell-cell interaction using receptor-ligand analysis}

CellPhoneDB v2.0 $(24,25)$ was used to identify significant $(p<0.05)$ potential cell-cell ligand-receptor interactions for the entire healthy adult, $\mathrm{AD}$ and psoriasis datasets, using 1000 iterations of data permutations. A minimum threshold of expression proportion of $10 \%$ was set for any ligand or receptor in a given cell type.

\section{Network analysis and clustered pathway annotation}

We ranked the differential expression $(\log 2 \mathrm{fc})$ of genes between the analogous cell clusters in healthy and disease states using the Wilcoxon rank sum test with Benjamini and Hochberg method adjusted FDRs, for over-representation analysis (ORA) using Gprofiler2 package in R to query two databases simultaneously (Reactome, Gene Ontology (GO) Biological Process) (Table S5). We derived statistical significance $(q<0.05)$ for each gene set enrichment and performed Markov clustering (MCL) using the MCL package in $\mathrm{R}$ to derive network neighborhoods based on shared genes between the gene sets. The gene set clusters were annotated using the AutoAnnotate Cytoscape package. Clusters were ranked by the mean enrichment score of all gene sets within each cluster and manually curated based on biological significance. We used the ClusterProfiler tool in $\mathrm{R}$ to visualize gene set enrichment.

\section{Gene regulatory network prediction}

We used the iRegulon package in Cytoscape to generate candidate transcription factors predicted to control homeostatic dendritic cell maturation. We ran the model using a search space of $20 \mathrm{~kb}$ around the transcription start site and a ROC threshold for AUC calculation of 0.03 .

\section{Mass cytometry clustering analysis}

Data from peeled, digested epidermis and dermis from 4 donors was clustered separately using the cytofkit Bioconductor package. Data was down-sampled to a maximum of 100,000 cells per experiment, clustered transformed using the cytofAsinh method, clustered with Rphenograph and visualized as tSNE. A manual gating strategy displayed 
in Fig. S3 was used to overlay suggested cell identities onto the tSNE. Cell proportion bars were calculated as an average of 4 donors.

All p-values from statistical analyses are provided in Table S6.

94. D. Gerrelli, S. Lisgo, A. J. Copp, S. Lindsay, Enabling research with human embryonic and fetal tissue resources. Development. 142, 3073 (2015).

95. P. Bullen, D. Wilson, in Molecular genetics of early human development (Bios Scientific publishers, 1997), pp. 27-35.

96. W. M. Hern, Correlation of fetal age and measurements between 10 and 26 weeks of gestation. Obstet. Gynecol. 63, 26-32 (1984).

97. M. Uhlén, L. Fagerberg, B. M. Hallström, C. Lindskog, P. Oksvold, A. Mardinoglu, Å. Sivertsson, C. Kampf, E. Sjöstedt, A. Asplund, I. Olsson, K. Edlund, E. Lundberg, S. Navani, C. A.-K. Szigyarto, J. Odeberg, D. Djureinovic, J. O. Takanen, S. Hober, T. Alm, P.-H. Edqvist, H. Berling, H. Tegel, J. Mulder, J. Rockberg, P. Nilsson, J. M. Schwenk, M. Hamsten, K. von Feilitzen, M. Forsberg, L. Persson, F. Johansson, M. Zwahlen, G. von Heijne, J. Nielsen, F. Pontén, Tissue-based map of the human proteome. Science. 347, 1260419 (2015).

98. L. M. Schriml, C. Arze, S. Nadendla, Y.-W. W. Chang, M. Mazaitis, V. Felix, G. Feng, W. A. Kibbe, Disease Ontology: a backbone for disease semantic integration. Nucleic Acids Res. 40, D940-D946 (2012).

99. C. L. Smith, J. A. Blake, J. A. Kadin, J. E. Richardson, C. J. Bult, Mouse Genome Database (MGD)-2018: knowledgebase for the laboratory mouse. Nucleic Acids Res. 46, D836-D842 (2018).

100. S. L. Wolock, R. Lopez, A. M. Klein, Scrublet: Computational Identification of Cell Doublets in Single-Cell Transcriptomic Data. Cell Syst. 8, 281-291.e9 (2019).

101. V. A. Traag, L. Waltman, N. J. van Eck, From Louvain to Leiden: guaranteeing well-connected communities. Sci. Rep. 9, 5233 (2019).

102. S. A. Lambert, A. Jolma, L. F. Campitelli, P. K. Das, Y. Yin, M. Albu, X. Chen, J. Taipale, T. R. Hughes, M. T. Weirauch, The Human Transcription Factors. Cell. 172, 650-665 (2018). 


\section{Fig. S1. Skin dissociation and FACS enrichment}

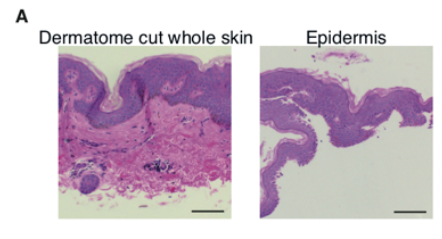

B
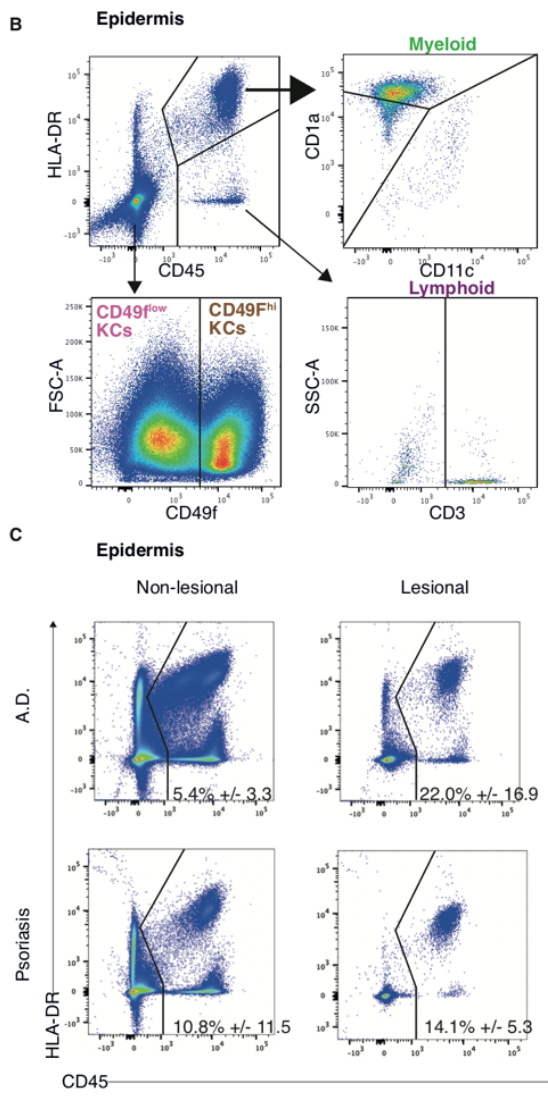

D

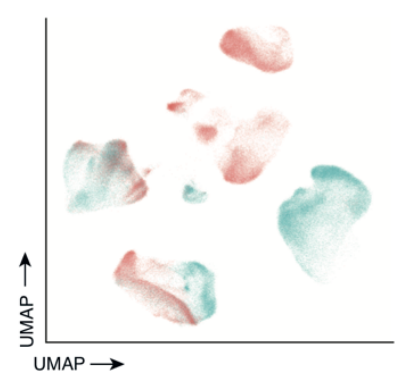

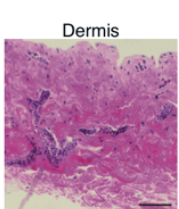

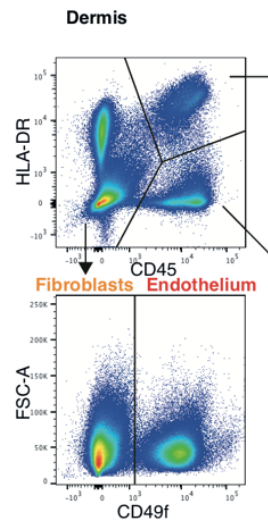

Dermis

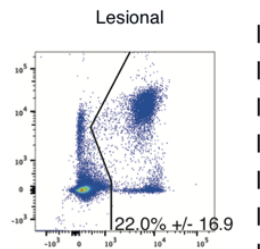

Non-lesional
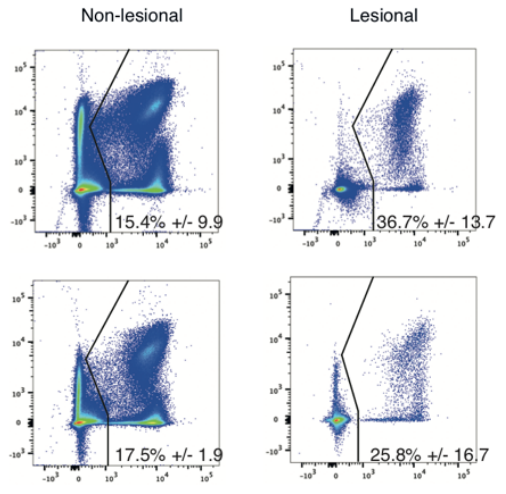

E
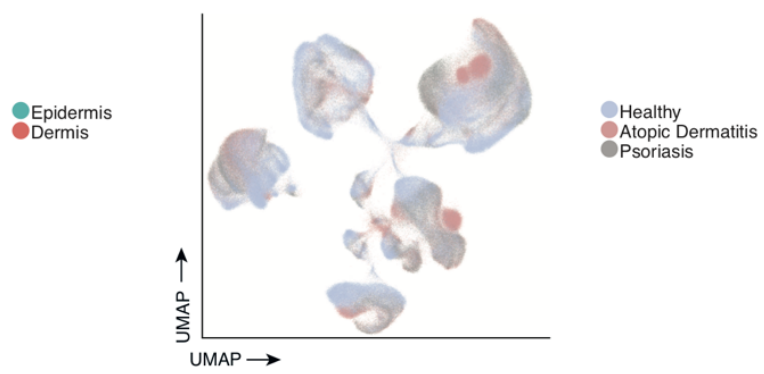

Fig. S1. Skin dissociation and FACS enrichment

(a) Left: H\&E stained image of skin fixed directly after dermatome cutting. Middle: Diagram of adult skin. Upper right: H\&E stained image of epidermis fixed directly after peeling. Lower right: H\&E stained image of dermis fixed directly after peeling. Scale 
bars represent $100 \mu \mathrm{m}$. Images representative of $n=3$. (b) FACS gating strategy used to collect cells for the healthy adult scRNA-seq experiments. Plots follow on from classical live singlet gating using DAPI and FSC-A/FSC-H respectively. (c) FACS gating strategy used to collect cells for the atopic dermatitis and psoriasis scRNA-seq experiments. Plots follow on from classical live singlet gating using DAPI and FSC-A/FSC-H respectively. (d) UMAP visualization shown in Figure 1B, colored by tissue origin of each cell. (e) UMAP visualization of all cells from adult healthy, atopic dermatitis and psoriasis samples, colored by disease state. 


\section{Fig. S2. Single cell RNA seq quality control}

A
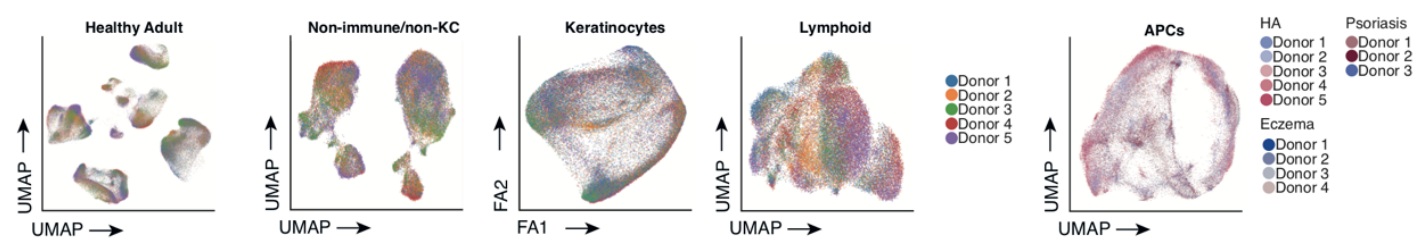

\section{B \\ Droplet}
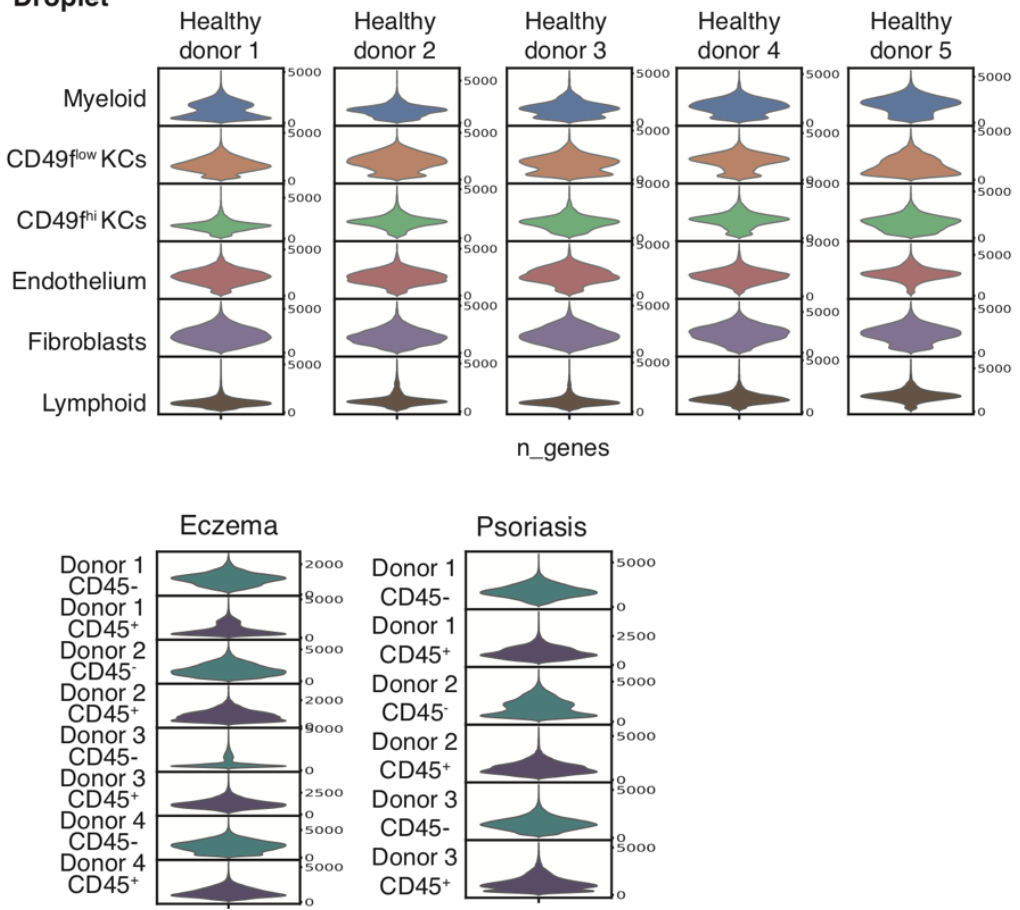

CD45

n_genes

Smart-seq2

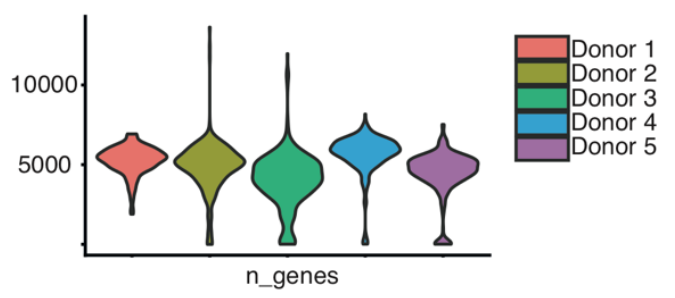

\section{Fig. S2. Single cell RNA seq quality control}

(a) UMAP and force directed graph visualizations shown in each main figure, colored by sample origin of each cell. (b) Violin plots showing the number of UMIs detected in each sample for Droplet (10x Genomics) and Smart-seq2 scRNA-seq profiling. 


\section{Fig. S3. Suspension mass cytometry analysis of adult skin}

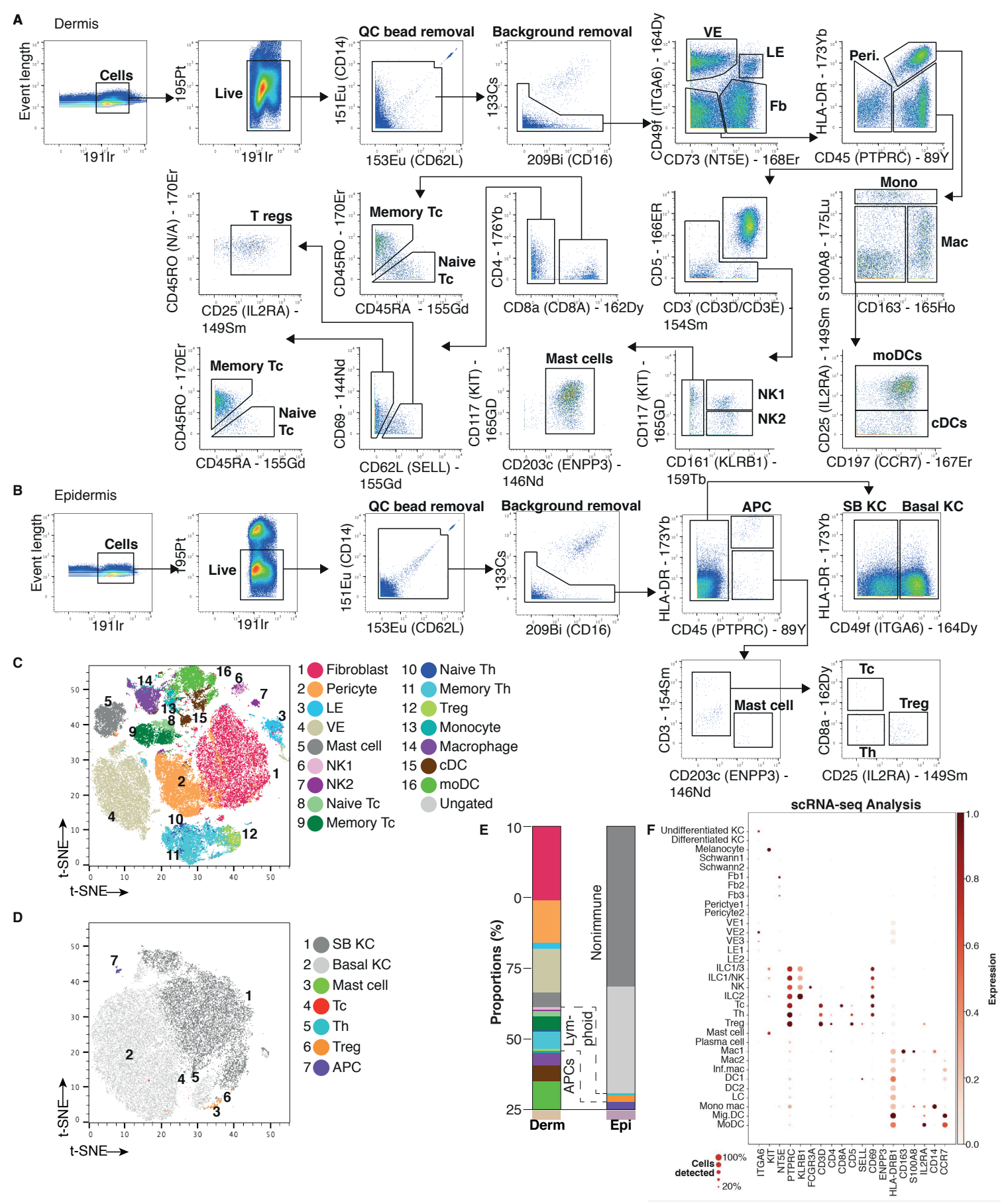

Fig. S3. Suspension mass cytometry analysis of adult skin

(a) Gating strategy for dermal cells analyzed by mass cytometry. (b) Gating strategy for epidermal cells analyzed by mass cytometry. The same gating strategy from (a) overlaid onto a tSNE plot of 100,000 downsampled cells. (d) The same gating strategy from (b) 
overlaid onto a tSNE plot of 100,000 downsampled cells. (e) Bar chart showing the frequency of cells in each gate, cell type colors match legend in Supplementary Figure 3D. All plots representative of $n=4$. (f) Expression of marker genes that were used for mass cytometry panel in healthy adult skin cell states. 


\section{Fig. S4. Stromal cells}

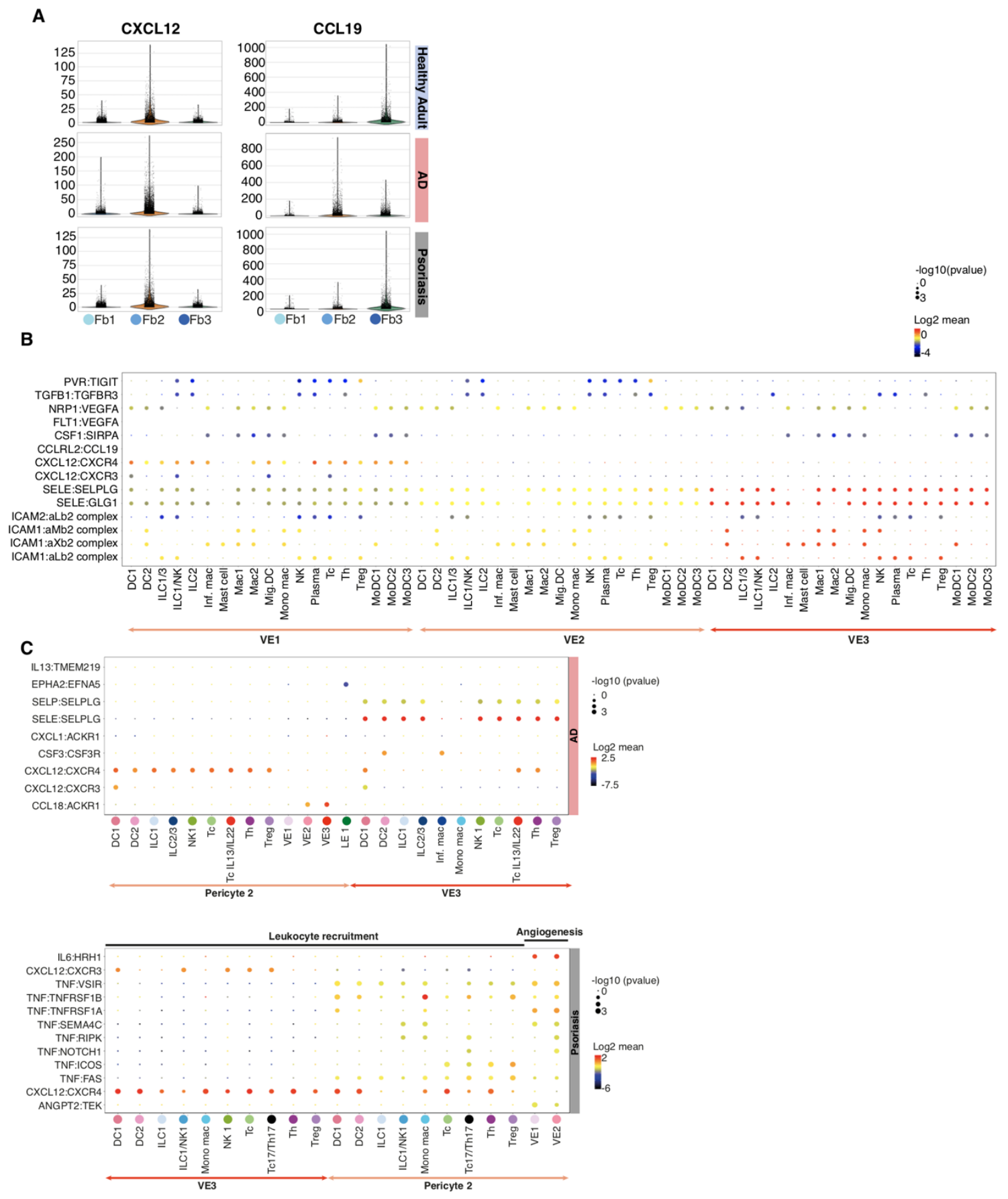

Fig. S4. Stromal cells

(a) Violin plots of F1, F2, F3 expression for CXCL12 and CXCL19. (b) CellPhoneDB predicted interactions between VE1, VE2 and VE3 and immune cells in healthy adult skin. (c) CellPhoneDB predicted interactions between VE3, pericyte2 and immune cells in $\mathrm{AD}$ (top panel) and psoriasis (bottom panel). 


\section{Fig. S5. Keratinocytes}
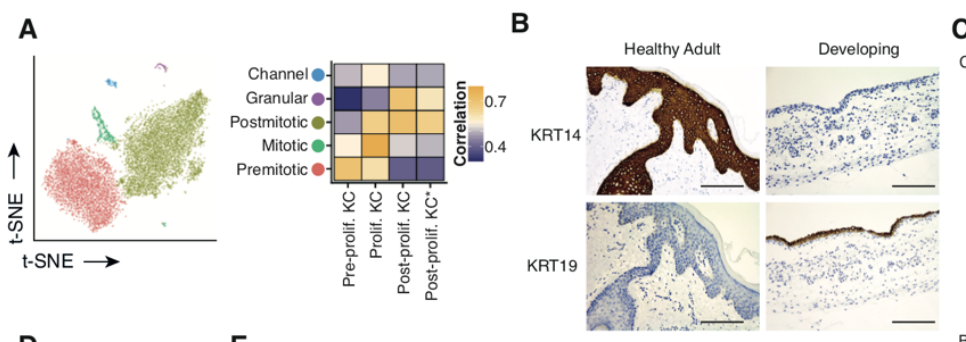

C

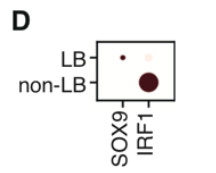

E
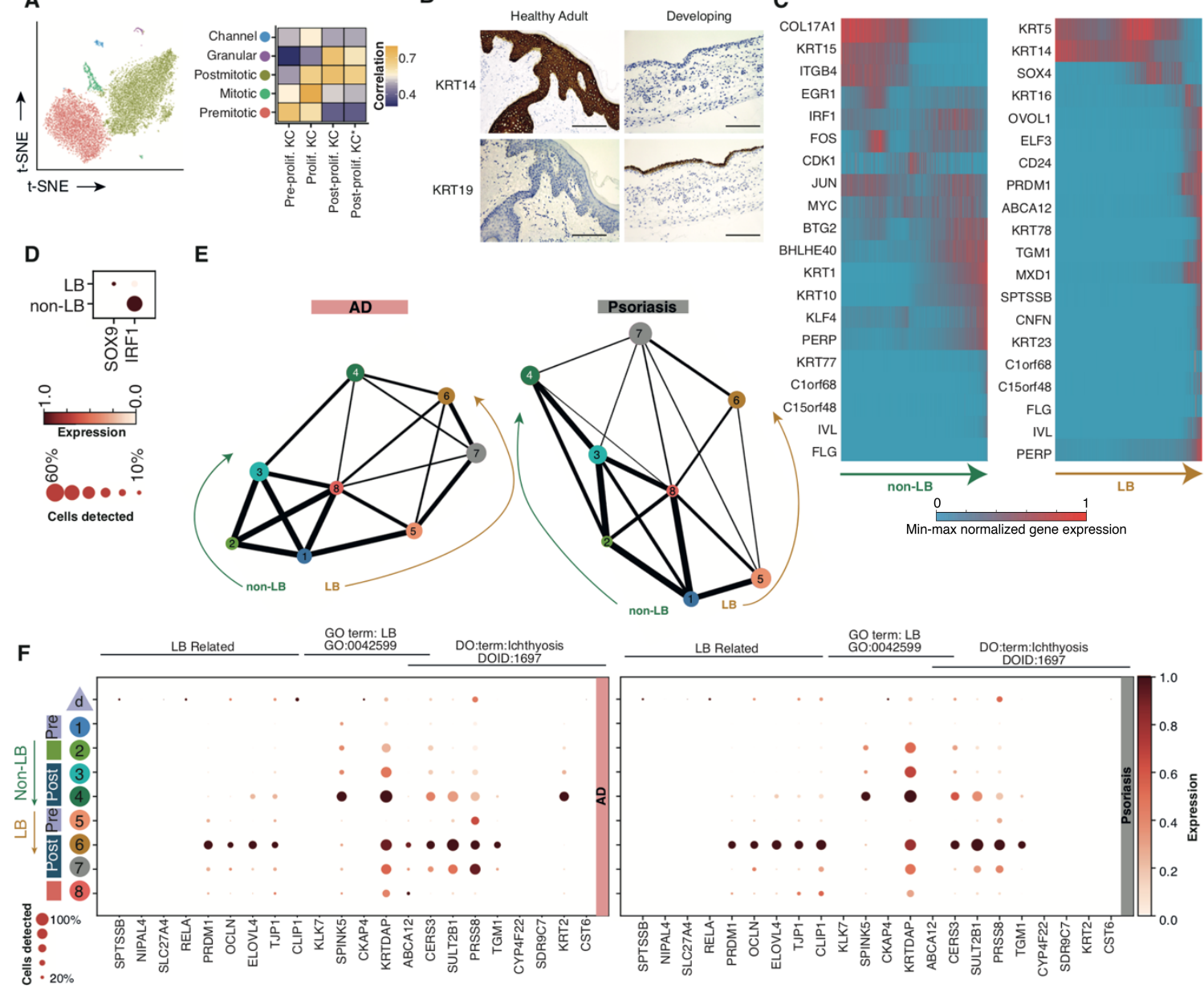

G

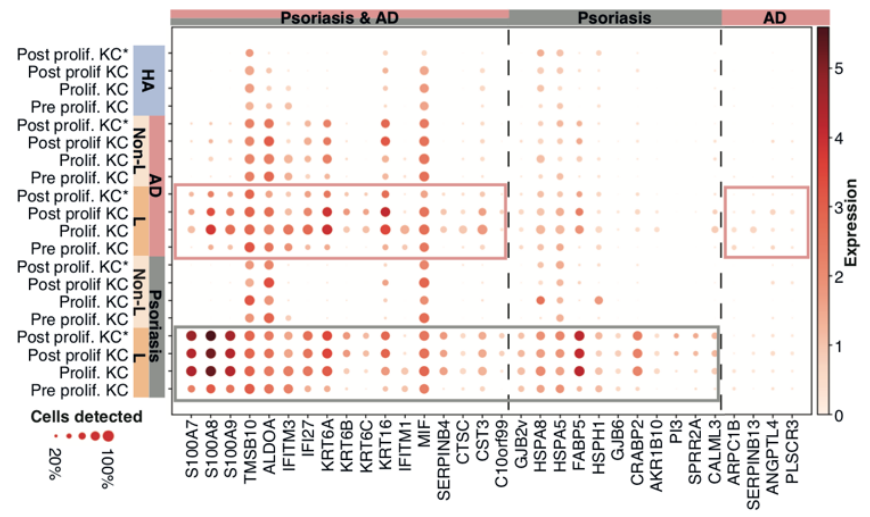

Fig. S5. Keratinocytes

(a) Left panel: tSNE plot of keratinocytes isolated from published healthy breast reduction sample data $(8)$, right panel: Spearman's correlation between keratinocyte cell types of our data. (b) IHC staining of adult and fetal skin for keratin 14 and keratin 19. 
Scale bars represent $100 \mu \mathrm{m}$. (c) Heatmaps of selected pseudotime genes from (Fig. 3d) across non-lamellar body expressing KCs (left) and lamellar body expressing KCs (right). (d) Dot plot showing the expression of SOXY and IRF1 in the two basal keratinocyte differentiation pathways. (e) PAGA showing the relative connectivity between the keratinocyte clusters in AD (left panel) and psoriasis (right panel). Arrows indicate the two differentiation pathways of basal keratinocytes to suprabasal: LB = lamellar body. (f) Dot plot of genes related to lamellar body production and ichthyosis on the clusters presented in (Fig. 3e) as well as fetal keratinocytes. (g) Dotplot showing top differentially expressed genes for psoriasis (grey rectangle) and AD (pink rectangle) keratinocytes from lesional skin compared to healthy skin. $\mathrm{HA}=$ healthy adult $(\mathrm{n}=5), \mathrm{AD}=$ atopic dermatitis $(n=4)$, psoriasis $(n=3), L=$ lesional, Non- $\mathrm{L}=$ non lesional. 
Fig. S6. Lymphoid cells

A
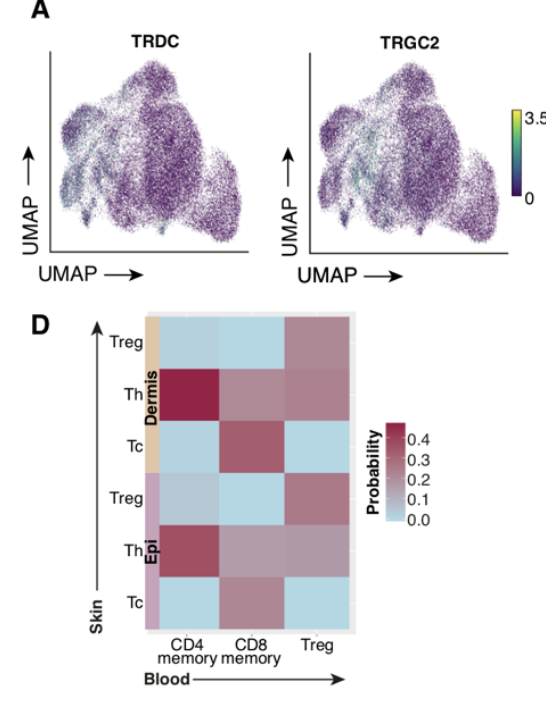

F

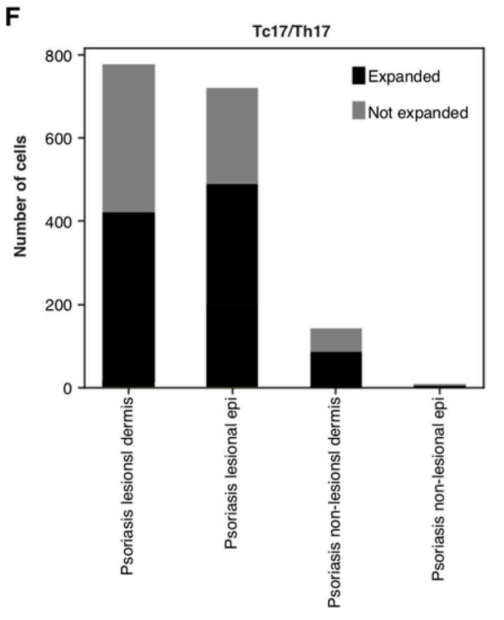

B

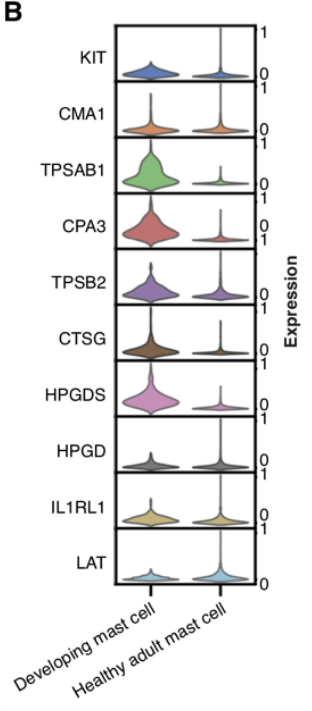

G

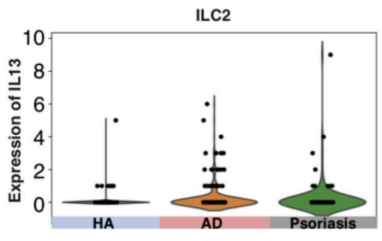

C

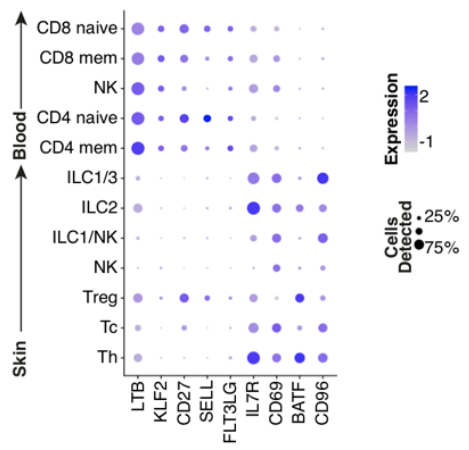

E

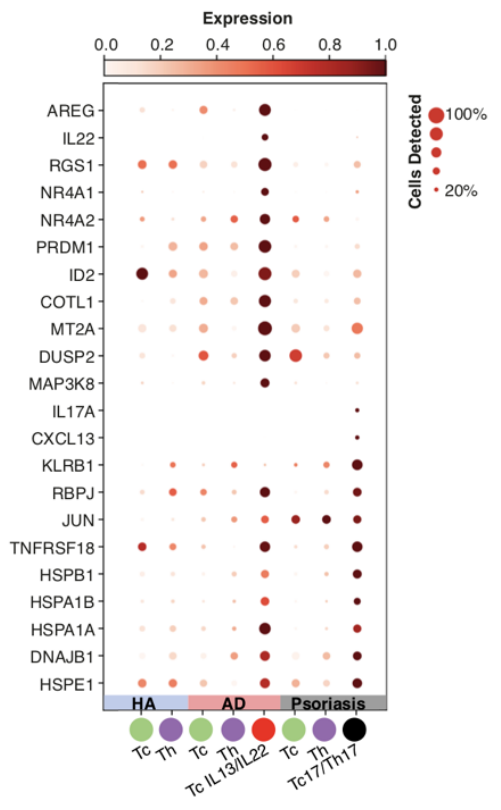

Fig. S6. Lymphoid cells

(a) Feature plots showing $\gamma \delta$ TCR gene expression on the UMAP plot shown in Figure 3A. (b) Violin plots showing the top 10 differentially expressed mast cell genes in fetal and adult skin mast eells. (c) Dot plot showing relative expression of skin residency related genes between blood and skin lymphocytes. (d) Heatmap of predicted closest match for blood $\mathrm{T}$ cells based on skin $\mathrm{T}$ cells as reference using the Transfer Anchors function in Seurat (e) Dot plot showing differentially expressed genes for T cell subtypes between healthy skin, AD and psoriasis. (f) Bar charts showing the number of expanded 
and not expanded Tc17/Th17 cells between psoriasis lesional and non lesional epidermis and dermis. $\mathrm{P}=$ psoriasis, $\mathrm{L}=$ lesional, $\mathrm{NL}=$ non lesional, Derm $=$ dermis, Epi = epidermis. $(\mathrm{J})$ Violin plot showing the expression of IL13 in healthy adult, AD and psoriasis skin. 
Fig. S7. Mononuclear phagocytes I

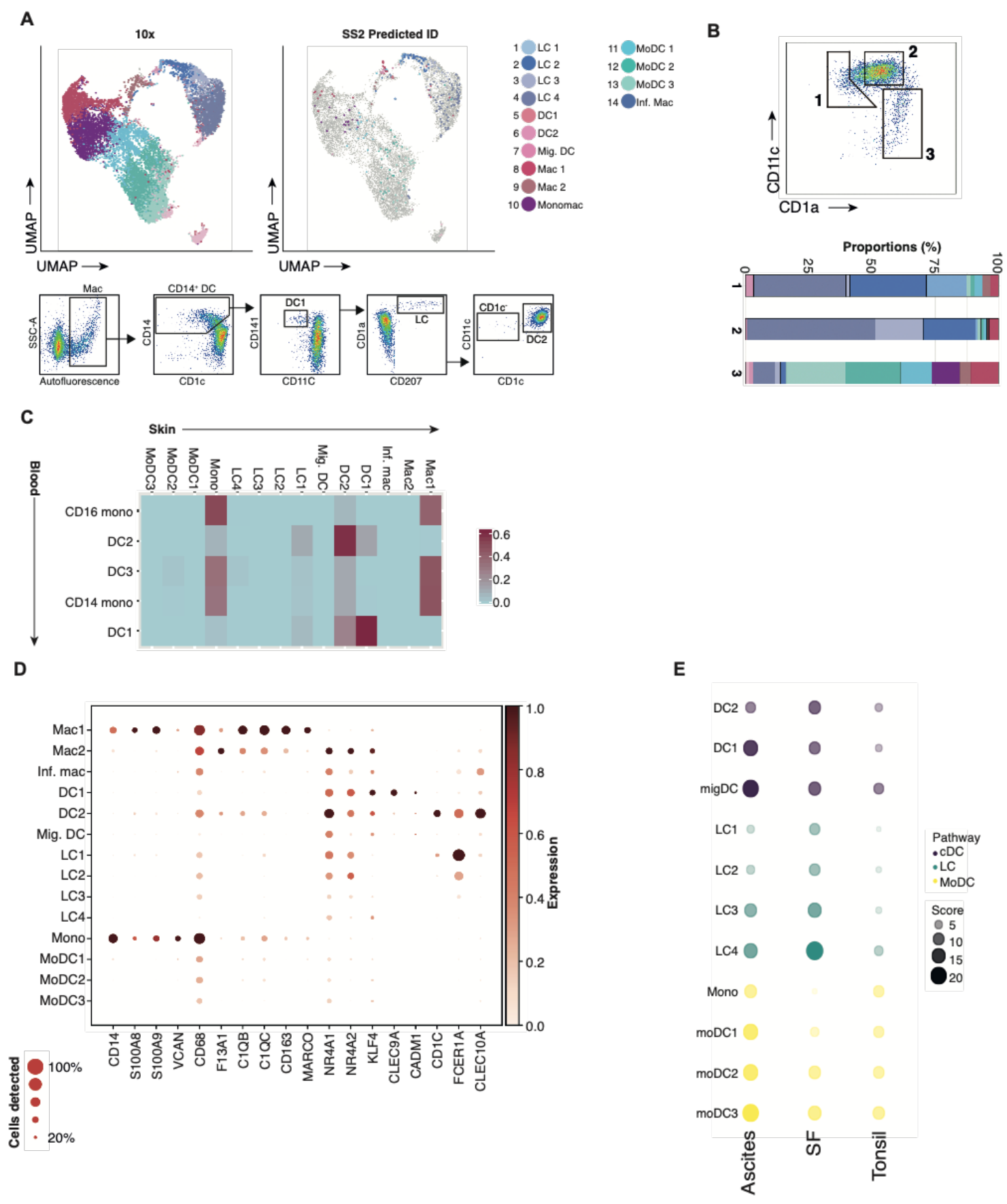

\section{Fig. S7. Mononuclear phagocytes I}

(a) UMAP visualization of merged droplet and Smart-Seq2 data for skin MP. Annotation of Smart-seq2 data derived following projection on to droplet data using the Seurat TransferAnchors function. (b) Stacked bar graph of Smart-seq2 cells within each MP 
FACS-sort gate (c) Heatmap of predicted closest match for blood MPs based on skin MPs as reference using the Transfer Anchors function in Seurat (d) Dotplot of expression of specific marker genes for blood MPs by skin MPs (e) Dotplot of enrichment of gene signatures derived from migratory DCs from other human tissues. 
Fig. S8. Mononuclear phagocytes II

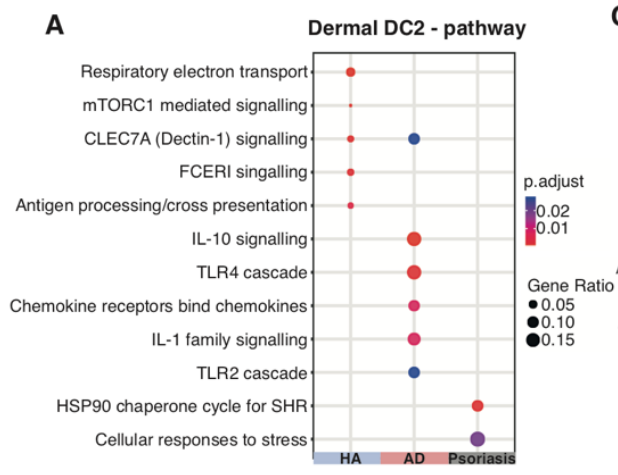

B

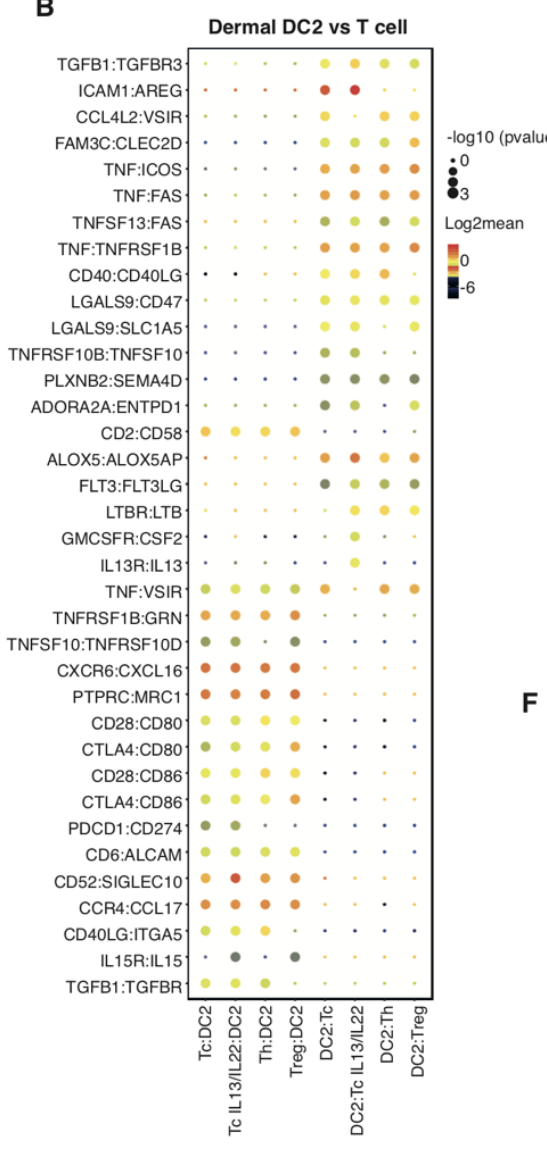

$\mathbf{F}$
C

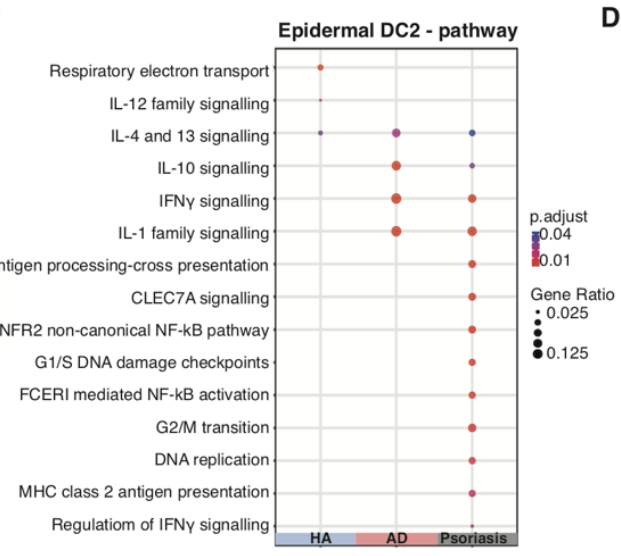

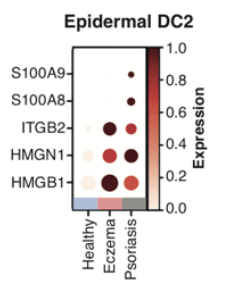

E
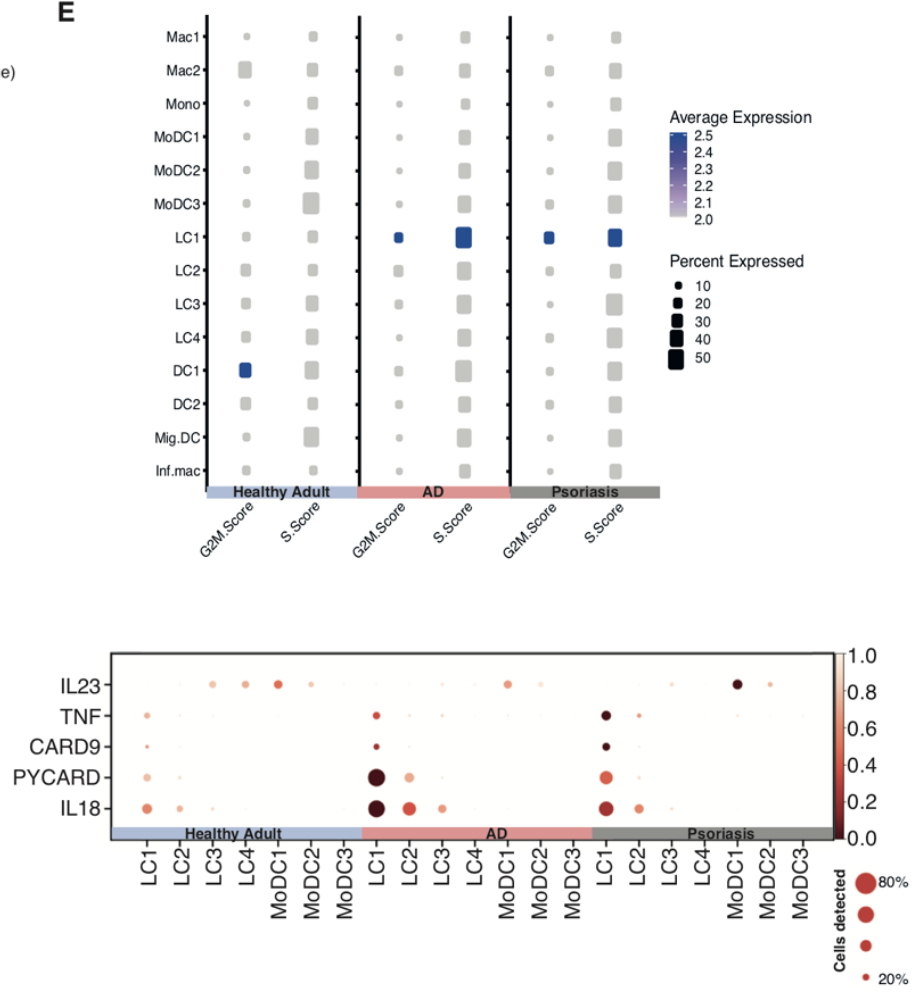

Fig. S8. Mononuclear phagocytes II

(a) Dotplot of predicted functional modules within DEGs of dermal DC2 between health, $\mathrm{AD}$ and psoriasis. (b) CellPhoneDB predicted interactions between dermal DC2 and each 